AperTO - Archivio Istituzionale Open Access dell'Università di Torino

\title{
Cav1.2 channelopathies causing autism: new hallmarks on Timothy syndrome
}

\section{This is the author's manuscript}

Original Citation:

Availability:

This version is available http://hdl.handle.net/2318/1785552

since 2021-06-30T09:16:27Z

Published version:

DOI:10.1007/s00424-020-02430-0

Terms of use:

Open Access

Anyone can freely access the full text of works made available as "Open Access". Works made available under a Creative Commons license can be used according to the terms and conditions of said license. Use of all other works requires consent of the right holder (author or publisher) if not exempted from copyright protection by the applicable law. 


\section{Invited Review}

\section{Cav1.2 channelopathies causing autism: new hallmarks on Timothy syndrome}

Andrea Marcantoni, 1

Chiarc AQ1 Calorio, 1

Enis Hidisoglu, 2

Giuseppe Chiantia, 1

Emilio Carbone, $1 \square$

Emailemilio.carbone@unito.it

1 Department of Drug Science, Laboratory of Cellular and Molecular Neuroscience, N.I.S. Centre, Corso Raffaello 30, 10125 Torino, Italy

2 Department of Biophysics, Faculty of Medicine, Akdeniz University, Antalya, Turkey

Received: 11 June 2020 / Accepted: 26 June 2020

\section{Abstract}

Cav1.2 L-type calcium channels play key roles in long-term synaptic plasticity, sensory transduction, muscle contraction, and hormone release. De 
novo mutations in the gene encoding Cav1.2 (CACNA1C) causes two forms of Timothy syndrome (TS1, TS2), characterized by a multisystem disorder inclusive of cardiac arrhythmias, long QT, autism, and adrenal gland dysfunction. In both TS1 and TS2, the missense mutation G406R is on the alternatively spliced exon 8 and 8A coding for the IS6-helix of Cav1.2 and is responsible for the penetrant form of autism in most TS individuals. The mutation causes specific gain-of-function changes to Cav1.2 channel gating: a "leftward shift" of voltage-dependent activation, reduced voltage-dependent inactivation, and a "leftward shift" of steady-state inactivation. How this occurs and how Cav1.2 gating changes alter neuronal firing and synaptic plasticity is still largely unexplained. Trying to better understanding the molecular basis of Cav1.2 gating dysfunctions leading to autism, here, we will present and discuss the properties of recently reported typical and atypical TS phenotypes and the effective gating changes exhibited by missense mutations associated with long QTs without extracardiac symptoms, unrelated to TS. We will also discuss new emerging views achieved from using iPSCs-derived neurons and the newly available autistic TS2-neo mouse model, both appearing promising for understanding neuronal mistuning in autistic TS patients. We will also analyze and describe recent proposals of molecular pathways that might explain mistuned $\mathrm{Ca}^{2+}$-mediated and $\mathrm{Ca}^{2+}$-independent excitation-transcription signals to the nucleus. Briefly, we will also discuss possible pharmacological approaches to treat autism associated with L-type channelopathies.

\section{Keywords}

L-type channelopathies

Gain-of-function mutations

Window $\mathrm{Ca}^{2+}$ currents

Neuronal mistuned $\mathrm{Ca}^{2+}$ signals

iPSCs

TS2-neo mouse model

Andrea Marcantoni and Chiara Calorio contributed equally to this work.

This article is part of the special issue on Channelopathies: from mutation to diseases in Pflügers Archiv—European Journal of Physiology

\section{Introduction}


Cav1.2 (encoded by the gene CACNA1C) is an L-type calcium channel with broad tissue expression profile, including cardiac and neuronal tissues, smooth muscle, pituitary, and adrenal glands $[21,23,30,103]$. Cav1.2 channels open upon cell depolarization to enable $\mathrm{Ca}^{2+}$ influx and initiate intracellular $\mathrm{Ca}^{2+}$ mediated signaling $[44,47]$. Alterations in intracellular $\mathrm{Ca}^{2+}$ signaling have been widely associated with neuropsychiatric diseases $[9,13,48]$. This is confirmed by genome-wide association studies (GWAS) of patients with bipolar disorder, schizophrenia, and autism spectrum disorders (ASD) in which have been identified gain- (GOF) and loss-of-function (LOF) mutations in CACNA1C [34, $40,62,78]$. Despite the clear indications of genetic changes in Cav1.2 function, little is known on how Cav1.2 affects the key cellular and molecular processes that lead to neurodevelopmental psychiatric disorders.

Timothy syndrome (TS), also known as long QT syndrome 8 (LQTS8), is a rare multiorgan $C A C N A 1 C$ channelopathy characterized by cardiac arrhythmias, long QTs, syndactyly, dysmorphic facial features, intermittent hypoglycemia, immune deficiencies, and neurodevelopmental disorder $[86,87]$. TS is associated with a de novo single point GOF mutation in CACNA1C, the gene encoding the $\alpha 1$ pore-forming subunit of Cav1.2 channels and occurs in two major forms (TS1 and TS2), depending on whether the point mutation appears on exon 8A [87] or exon 8 [86]. The two exons code for the IS6 helix of the Cav1.2 channel controlling the voltage dependence of channel activation and inactivation. In the TS type 1 (TS1), the mutation occurs at Gly406 (G406R) in close proximity to the intracellular I-II loop of exon 8A. In TS type 2 (TS2), the mutation occurs either at Gly406 (G406R) or at Gly402 (G402S) within exon 8, which is highly expressed in the brain and heart (80\%) and to a lesser extent in the adrenal glands [86]. Both gain-of-function mutations affect Cav1.2 gating by drastically reducing channel inactivation and increasing $\mathrm{Ca}^{2+}$ influx during cell depolarization. This causes prolongation of cardiac action potential (AP), long QT, and ventricular arrhythmias that are the most severe pathological conditions of TS patients [12].

TS1 and TS2 patients present autistic forms of behavior, which are more evident in TS2 patients since exon 8 is more expressed in the brain than exon $8 \mathrm{~A}$. Curiously, TS2 patients carrying the G402S mutation exhibit severe cardiopathies but are neurologically intact while patients with G406R mutation display both cardiopathies and autism spectrum disorders (ASD) $[35,45,86]$. Recent findings suggest that the ability of the G406R vs. G402S mutation in inducing neurological abnormalities $[52,84]$ may be linked to a gating change associated with Cav1.2 channel activation. Indeed, G406R and G402S mutations have opposing effects on the voltage dependence of Cav1.2 channel activation. 
Mutant G406R shifts the voltage dependence of activation toward more negative potentials, whereas G402S shifts the activation in the opposite direction [28, 76]. A marked negative shift of voltage-dependent activation favors L-type channel openings near resting potentials, thus causing basal increases of inward $\mathrm{Ca}^{2+}$ fluxes that could boost $\mathrm{Ca}^{2+}$-mediated neuronal gene expression. Well-resolved negative shifts of the voltage dependence of Cav channels are also characteristic of point mutations A749G, V401L, and S652L of the L-type Cav1.3 $\alpha 1$-subunit, coded by the CACNA1D gene, identified in individuals with ASD or global developmental delay $[46,72,73]$. Of relevance, in the Cav1.3 GOF mutations, channel inactivation is delayed only in the V401L mutation, while inactivation is accelerated in A749G and S652L, suggesting that "slowing" or "acceleration" of Cav1 channels inactivation is most likely not relevant for altering neurodevelopmental disorders leading to ASD.

TS is one of the most penetrant monogenic forms of autism, with a percentage as high as $60-80 \%[17,86,87]$. As for other Cav channelopathies, TS is widely studied using either heterologous expression of Cav1.2 mutants in clonal cell lines $[8,14,28,31,87,98,101]$ or neurons induced from pluripotent stem cells (iPSCs) of individuals with TS [51, 69-71, 102]. The first approach has been fundamental to identify the hallmarks of Cav1.2 activation and inactivation gating changes induced by the TS mutations, to test blockers of the TS-mutated Cav1.2 channels and design in silico models of TS-altered AP waveforms. The second approach allowed recognizing defects in $\mathrm{Ca}^{2+}$ signaling in iPSC-induced neurons of TS patients that induce major alterations in the regulation of gene transcription downstream of activity-dependent $\mathrm{Ca}^{2+}$ entry via Cav1.2 channels $[51,69,71]$.

An alternative approach to study TS-induced cellular and molecular changes associated with ASD is the use of the recently available knock-in TS2-neo (G406R) mouse model. The mouse exhibits social impairment, communication deficits, and repetitive behaviors as well as poor sensorimotor learning reminiscent of autism [4, 7, 10, 77]. TS2-neo mice have normal weight [49] and largely normal brain size [4], but display structural anomalies in the medial geniculate nucleus (MGN) [77], altered brain activities that are common across several ASD mouse models [29], and enhanced oligodendrocyte progenitor cells development and oligodendrocyte myelination [24]. The TS2-neo mouse has been recently used to study the cellular and molecular changes of adrenal chromaffin cells (CCs) [20] that could explain the severe bilateral adrenal gland dystrophy reported after post-mortem autopsy of a 2-month-old TS patient [50]. Using adrenal CCs of heterozygous TS2-neo mice, it could be shown that the G406R mutation prolongs the inactivation and shifts leftward the activation and steady-state inactivation of endogenous L-type channels, causing increased 
resting $\mathrm{Ca}^{2+}$ influx ("window" $\mathrm{Ca}^{2+}$ current) [20]. The increased basal $\mathrm{Ca}^{2+}$ causes marked reduction of Nav channel density, switches normal AP firing from tonic to bursts, reduces mitochondrial metabolism, induces cell swelling, and decreases catecholamine release, providing evidence that $\mathrm{CC}$ malfunction derives from the altered Cav1.2 channel gating.

Here, we will provide a detailed review of the classical and new hallmarks of TS that could cause altered neuronal firing, neurodevelopmental disorders, and ASD. We will discuss new forms of typical and atypical TS recently associated with GOF mutations of $C A C N 1 C$ and the rationale of newly proposed Cav1.2mediated excitation-transcription (E-T) coupling models that triggers gene activation via a cascade of protein-protein interactions [51, 52, 83, 84]. We will also discuss new hallmarks of TS pathophysiology emerging from studies with the TS2-neo mouse model and iPSC-induced neurons and highlight some new pharmacological evidence for the treatment of TS, promoting the management of this rare disease.

\section{The Cav 1.2 Cav1.2 1.2 of the same size of $C$ channel structure}

Cav1.2 channels are hetero-oligomeric complexes that include the pore-forming transmembrane $\alpha 1$-subunit, the intracellular $\beta$-subunit, and the extracellular $\alpha 2 \delta$ subunit. The $\alpha 1$-subunit is composed of more than 1800 amino acids and is responsible for most of the pharmacological and gating properties of the channel. The other components serve as auxiliary subunits and modulate the function of the channel. The structural topology of the $\alpha 1$-subunits is highly conserved among the members of the Cav1 L-type channel family and is composed of the cytoplasmic $\mathrm{N}$ - and $\mathrm{C}$-terminal domains and four homologous repeats (I-IV) with six transmembrane segments each (S1-S6 $\alpha$-helices) (Fig. 1).

\section{Fig. 1}

Predicted topology of the pore-forming Cav1.2 $\alpha 1$-subunit showing the location of TS1 and TS2 mutations and interactions with $\beta$ subunit and $\mathrm{Ca}^{2+} \mathrm{CaM}$. The $\alpha 1$ subunit consists of four homologous repeats (I-IV), each comprising six transmembrane helices (S1-S6). From each repeat, S1-S4 form the voltage sensors. The S4 helices (orange) contain positive gating charges. S5-S6 with their connecting P loop form the ion conducting pore. The S4-S5 loop links the voltage sensor movements to the pore opening. The SH3-GK domains and the positions of the $\beta$ subunit/AID complex at the I-II linker and $\mathrm{Ca}^{2+}-\mathrm{CaM}$ in proximity of PreIQ and IQ domains on the $\mathrm{C}$-terminal are indicated (derived from ref. $(23,61)$ ) 


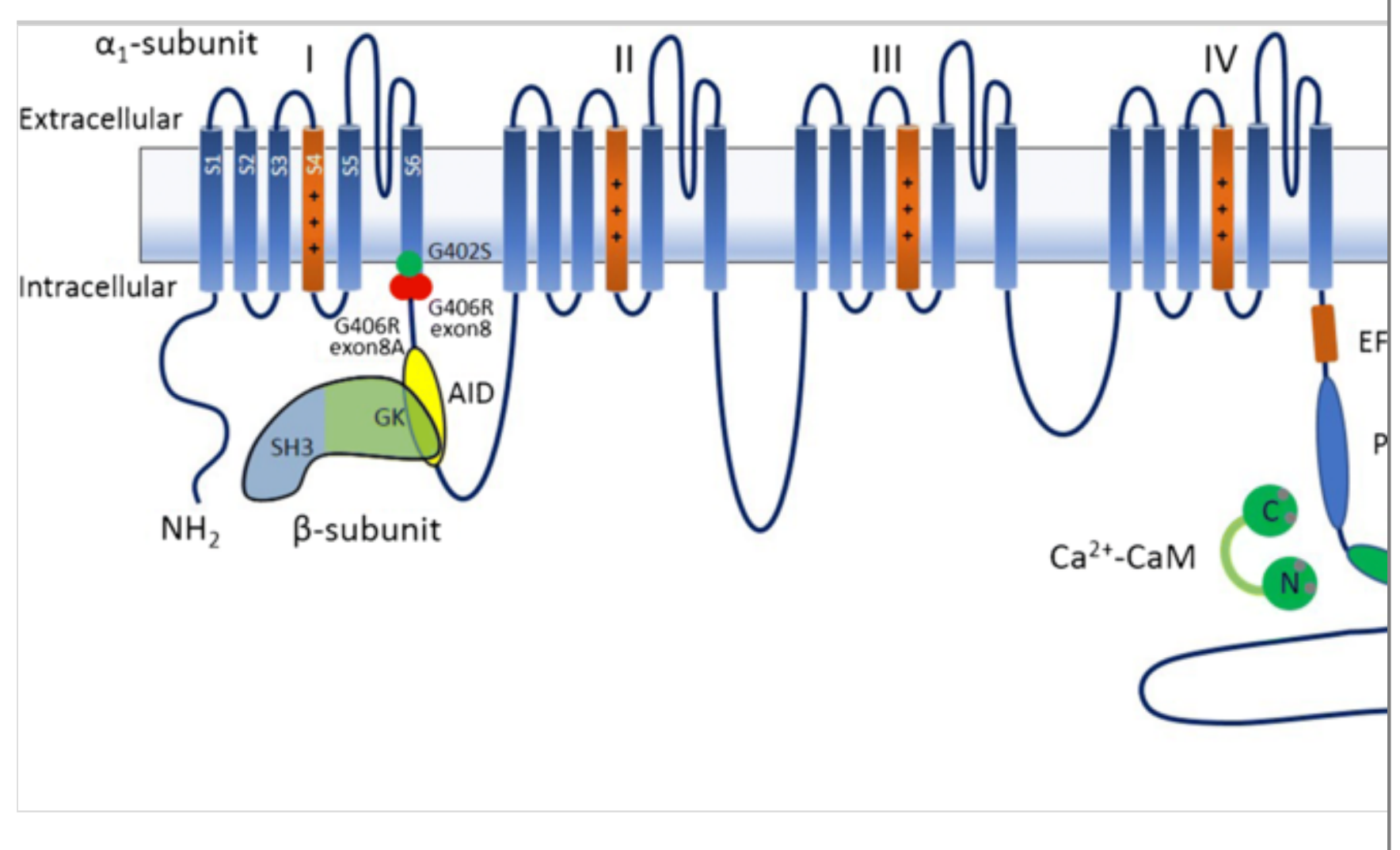

The voltage sensor module Segments $\mathrm{S} 1-\mathrm{S} 4$ of each repeat form the voltagesensing domain (VSD) and segments S5-S6 with the connecting P loop form the pore domain and selectivity filter $[23,44]$. The $\mathrm{S} 4 \alpha$-helices contain four to five positively charged amino acid residues (arginines or lysines) that serve as the actual voltage sensors of the voltage-dependent gating mechanism. The S1-S3 helices of the VSD contain several negatively charged amino acids and polar residues that stabilize the positively charges of S4 [93]. Upon depolarization, the S4 segments move outward, and their movement is transmitted through the S4S5 linkers to the cytoplasmic ends of S5 and S6 helices, causing a conformational change that opens the channel pore [92].

The voltage-dependent and $\mathrm{Ca}^{2+}$-dependent inactivation The inner part of the S6 segments that lines the inner vestibule of the pore form part of the docking site for the fast voltage-dependent inactivation (VDI) gate [85, 91]. In response to membrane depolarization, the $\mathrm{S} 6$ segments undergoes a slight conformational change that unmasks the docking sites at the cytoplasmic ends of the segments to which the intracellular I-II linker gating particle binds and block $\mathrm{Ca}^{2+}$ permeation [89]. The I-II linker acts as a "hinged lid" that physically occludes the pore by docking to the cytoplasmic ends of the S6 segments [88]. Other intracellular regions, such as the $\mathrm{N}$ - and C-termini, as well as the III-IV linker both directly or allosterically interact with the inactivation machinery and play a critical role in the regulation of VDI [91]. 
The $\mathrm{Ca}^{2+}$-dependent inactivation (CDI) of Cav1 channels serves as the autoinhibitory control for Cav1 channels to control the levels of intracellular calcium and occurs in addition to VDI during depolarization. Calmodulin (CaM) can be considered an additional channel subunit and has a prominent role in the intrinsic mechanisms of CDI. Upon $\mathrm{Ca}^{2+}$ binding, $\mathrm{CaM}$ undergoes a conformational change that interacts with additional C-terminal effector sites promoting channel inactivation. The long cytoplasmic $\mathrm{C}$-terminal region of the $\alpha 1$-subunits contains the effector domains for $\mathrm{Ca}^{2+}-\mathrm{CaM}$ modulation (Fig. 1). Specifically, $\mathrm{Ca}^{2+}-\mathrm{CaM}$ binds to an isoleucine-glutamine "IQ" domain located in the C-terminal cytoplasmic tail $\sim 150$ amino acids downstream the last transmembrane segment, IVS6 (for details see [61]). Besides being the locus of $\mathrm{CDI}$, the $\mathrm{C}$-terminus is the target of numerous protein-protein interaction and serves as an important modulatory domain for Cav1.2 channels.

The AID/ $\beta$-subunit complex Cav1.2 channels strictly require an auxiliary $\beta$ subunit for trafficking the channels to the plasma membrane, fine-tuning channel gating, and regulating channel modulation by other proteins and signaling molecules [18]. All Cav1.2 $\beta$-subunits $(\beta 1-\beta 4)$ bind with high affinity ( 2 to $54 \mathrm{nM}$ ) to the 18 amino acid $\alpha 1$-subunit interaction domain (AID), which is located in the first half of the intracellular I-II linker of Cav1.2 $\alpha 1$-subunits [74] (Fig. 1). $\beta$-subunits are proteins of $\sim 60 \mathrm{kDa}$, consisting of a conserved core region flanked by non-conserved $\mathrm{N}$ - and $\mathrm{C}$-termini $[26,43,66]$. The core region of the $\beta$-subunits is composed of two highly conserved regions homologous to the Src homology 3 (SH3) and guanylate kinase (GK) domains, connected by a weakly conserved HOOK domain that recapitulate many key functions of the subunits [19]. Crystal structure studies show that the AID binds to a hydrophobic groove in the GK domain termed the AID-binding pocket (ABP) [61] (Fig. 1). The extensive and predominantly hydrophobic interactions between AID and ABP account for the high affinity of the AID/ $\beta$-subunit binding. Of relevance for the pathophysiology of TS is the possible role of $\beta$-subunits as transcriptional regulators that has been demonstrated for both short splice variants and fulllength $\beta$-subunits $[18,90]$. There is now increasing evidence that $\beta$-subunits can translocate to the nucleus under specific stimuli and induce transcriptional regulation [32, 83]. The AID I-II linker domain is closely located to the G406R mutation in IS6, and it is thus likely that conformational changes of TS mutant Cav1.2 channels affect the $\beta$-subunit binding to induce ET signals and gene transcription in neurons $[32,84]$.

\section{Cav 1.2 Cav1.2 1.2 of the same size as C gain-of-function mutations causing typical TS phenotypes}


Given the importance of Cav1.2 for many body functions, it was somewhat surprising that many years after the L-type channel genes were identified [22]; no mutations were discovered in Cav1.2 channels. The absence of Cav1.2 channelopathies was even more surprising since deletion of the pore-forming Cav1.2 channel gene in mice results in embryonic lethality $\sim 2$ weeks post coitum [80]. This suggested that mutations causing critical changes in Cav1.2 channels are very likely embryonically lethal, and mutations associated with weak effects on Cav1.2 channel gating can be well tolerated, and individuals may show no obvious phenotypes [53].

The typical TS phenotypes In 2004, TS was reported for the first time as a novel disorder associated to an L-type channel mutation identified as a sporadic heterozygous single point mutation in the Cav1.2-encoding gene CACNA1C [87]. TS individuals were characterized as affected by a multiorgan dysfunction with lethal arrhythmias (long QT), syndactyly, congenital heart disease, immune deficiency, craniofacial abnormalities, hypoglycemia, cognitive abnormalities, and autism. A single missense mutation in position G406R in the alternatively spliced exon 8A was identified as the cause of TS1. A year later, the same group reported an analogous de novo G406R mutation and a second G402S missense mutation in exon 8 causing severe long QT syndromes, syndactyly, and other TS phenotypes [86], identified as TS2 (Fig. 1). Mutation G406R is in both exon 8A and exon 8 while mutation G402S is only on exon 8 . Both exon 8 and $8 \mathrm{~A}$ code for the IS6 segments of CACNA1C. The two mutations occur near the end of the IS6 segment upstream of the I-II linker responsible for channel inactivation. Mutations of G406 into an arginine and G402 in to a serine attenuate the rigid $\alpha$ helix and thus weaken Cav1.2 channel inactivation. Both mutations of alternatively spliced exon $8 \mathrm{~A}$ alter also Cav1.2 channel activation that are controlled by the end groups of the four S6 $\alpha$-helices lining the pore (see above). Specifically, the mutations cause a GOF of Cav1.2 activity by slowing the time course of channel inactivation (less complete fast inactivation), thus prolonging $\mathrm{Ca}^{2+}$ influx during steady depolarization. This accounts for the prolonged cardiac AP duration and long QT syndrome, which is more pronounced in TS2 patients since exon 8 is more highly expressed in cardiac than in smooth muscle tissue $(80 \%$ vs. $20 \%)[86,87]$. The TS mutations account also for some of the extracardiac phenotypes observed in TS patients. For instance, hyperinsulinemia and corresponding intermittent hypoglycemia and craniofacial abnormalities reported in most TS patients. Cav1.2 calcium channels are the major contributors of $\mathrm{Ca}^{2+}$-dependent insulin secretion from pancreatic $\beta$ cells [100] and drive hypertrophy and hyperplasia in chondrocytes within the developing mandible [75]. 
Data of many groups indicate that G406R and G402S mutations cause a prominent loss of the VDI rather than an attenuation of the CDI. Indeed, the reduced fast inactivation is clearly visible when recording $\mathrm{Ba}^{2+}$ currents through TS1 or TS2 mutant Cav1.2 channels, either heterologously expressed in HEK 293 cells $[8,76,86,87,101]$ or isolated from primary cultures of TS2-mutated excitable cells [20]. There is, however, evidence for a reduced CDI in adult guinea pig myocytes transfected with G406R and G402S mutated channels that accounts for the different threshold behavior in the induction of arrhythmias associated with the two TS mutations [28]. A reduced CDI is also evident in the corresponding G406R and G406S Cav1.2-mutated channels of rabbit, heterologously expressed in Xenopus oocytes [76]. In silico modeling predicts that, due to the weakened VDI (or CDI), TS-mutated channels fail to close during the plateau phase of cardiac AP, thus increasing the inward $\mathrm{Ca}^{2+}$ current that markedly delay AP repolarization.

\section{The critical Cav 1.2 Cav1.2 gating changes leading to autism While} decreased VDI and CDI account for several of the phenotypic properties of TS, they hardly account for the autistic forms present in over three quarters of TS individuals. Several observations support this view. First, TS2 patients bearing the G402S mutation are neurologically intact $[35,45]$ despite causing an analogous reduction of VDI. Second, missense mutations of Cav1.3 channels in position V401L, S652L, and A749G associated with forms of autism or mental retardation cause either a decreased (V401L) or an increased VDI (S652L, A749G) [46, 72, 73]. Third, dendritic retraction occurring after expression of the G406R mutant channel in cultured neurons develop through a $\mathrm{Ca}^{2+}$-independent signaling process that is also activated in the presence of non-conductive G406R TS mutant channels [51]. All these results indicate that neuronal dysfunctions can proceed regardless of reduced VDI.

A gating parameter that appears very critical for the development of autism is the lowered threshold of Cav1.2 channel activation that is associated with the "negative shift" of voltage-dependent activation induced by the G406R TS mutation [20, 28, 52]. Substitution of Gly406 with a hydrophilic residue (Arg, Lys, Asp, Glu) invariably promote the activated state of Cav1.2 by shifting the voltage dependence of activation toward negative potentials. Maximal shifts occur for Asp (-7.3 mV) followed by Arg (-6.2 mV) substitution [76]. Charged residues replacing the stabilizing glycine at the 406 position of the IS6 segment are expected to increase the flexibility of the $\alpha$-helix that facilitates channel activation. At the same time, the G406R mutation acts on the I-II linker to weaken its folding back over the intracellular mouth of the pore, slowing the "hinged lid" type mechanism of channel inactivation. On the contrary, 
substitution of G402 with serine causes a positive shift of voltage-dependent activation $(+3.2 \mathrm{mV})$ [76]. The shift is confirmed by Dick et al. [28] in G402Stransfected adult myocytes from guinea pig $(\sim+13 \mathrm{mV})$. The negative voltage shift of Cav1.2 channel activation is thus very likely a key mechanism that may contribute to neuronal mistuning in developing neurons.

A second important parameter of great significance in L-type channel dysfunction associated with ASD and other forms of intellectual disabilities is the percentage of Cav1 channels that are open at resting potentials where neurons and excitable cells spend most of their time of activity (\% of channels availability). This determines the amplitude of the so-called "window $\mathrm{Ca}^{2+}$ current" that sets the steady influx of $\mathrm{Ca}^{2+}$ at rest but also establishes a significant open-closed channel kinetics that sustains Cav1.2 channel conformation changes at rest [20]. This current for the G406R TS2 mutant is significantly increased and shifted to more negative voltages than for WT channels ( [20] see below). Similar shifts are reported for the atypical TS mutation I1166T [16] and for the A749G, V401L, and S652L Cav1.3 mutations where steady-state inactivation (SSI(V); \% of channels availability) and channel conductance $\left(g_{\mathrm{Ca}}(\mathrm{V})\right)$ are systematically measured $[46,72,73]$. Notice that mutations I1166T, A749G, and S652 are L-type channel mutations associated with identified human phenotypes with autism or intellectual disabilities in which the rate of inactivation is increased rather than decreased as in TS1 and TS2 mutants (see below).

\section{Atypical Cav 1.2 Cav1.2 gain-of-function mutations causing TS}

Besides the two classical CACNA1C mutations causing TS (G406R and G402S), there are three recently reported cases of atypical Cav1.2 GOF mutations associated with long QT and extracardiac phenotypes occurring in exons other than exons $8 \mathrm{~A} / 8$ [16, 39, 68, 98] (Fig. 2). The first case is a de novo A1473G mutation occurring at the end of the Cav1.2 IVS6 segment (in exon 38) identified in a child diagnosed with markedly prolonged QT interval, dysmorphic facial features, syndactyly, joint contractures, and later profound developmental delay [39]. Functional studies of this mutation in heterologous expression systems were not reported but it is likely that the mutation is a GOF similar to the TS1 and TS2 mutations. Mutation A1473G is upstream the Cterminus and can possibly interact with the I-II linker, altering the flexibility of this intracellular region as described for the TS1 and TS2 mutations [39].

Fig. 2 
Scheme of the position of missense mutations within the Cav1.2 $\alpha 1$ subunit causing TS with autism, TS without autism, or simply LQTS type 8 without TS. The components of the four homologous repeats (I-IV) of the Ca1.2 $\alpha 1$ subunit are indicated as in Fig. 1. Circles indicate the position of missense mutations either causing TS associated to ASD (filled red), causing TS without ASD (filled green), or simply causing LQTS type 8 without TS syndrome (empty red). Mutations P381S, M456I, and G1783C are added as reported in ref. (36)

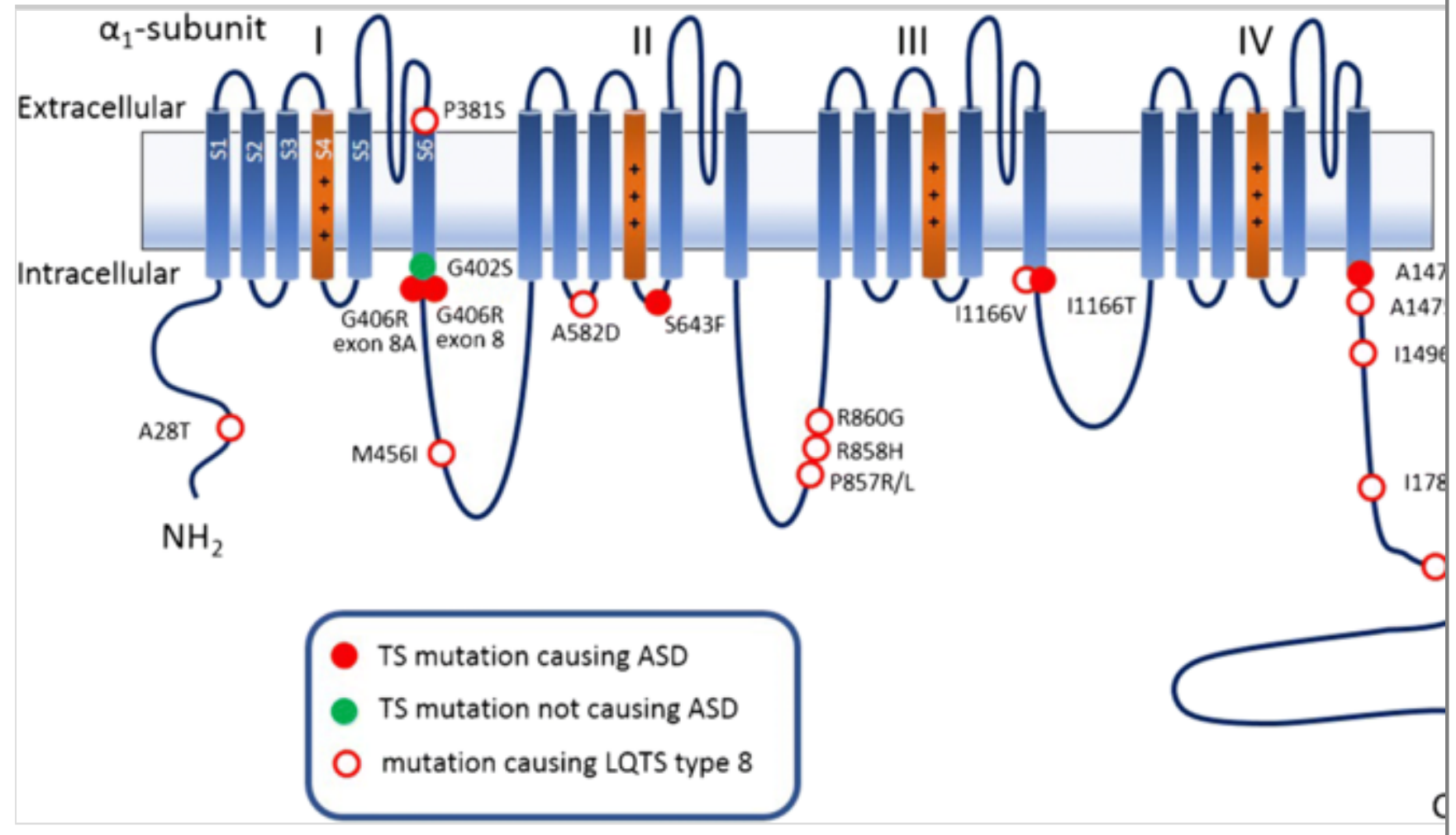

The second case is a de novo I1166T mutation within the III-IV linker (in exon 28) discovered through a whole exome sequencing (WES) in a subject with long QT, a patent ductus arteriosus, facial dysmorphisms, various digit abnormalities, intellectual impairment, and tooth decay [16]. A similar case with the same mutation, but without syndactyly, was reported also for a 1-year-old female identified in a study of 540 LQTS probands [98]. Mutant channels co-expressed in HEK 293 cells exhibit the typical negative voltage shift of channel activation and nearly no effect on SSI suggesting an increased window $\mathrm{Ca}^{2+}$ current near resting potentials. Inactivation was in one case unchanged [16], while in the other case was partially reduced [98] as expected from a Cav1.2 mutation causing TS. Possible reasons for this discrepancy could be their dependence on different $\beta 2$ - and $\alpha 2 \delta$-subunits used during the co-expression procedure [98]. Taken together, it is evident that the I1166T mutation causes a GOF phenotype resembling classical TS1 and TS2. 
The third case is a de novo S436F mutation located in the intracellular S4-S5 linker of domain II, identified in a TS proband without syndactyly but with severe cardiac phenotype [68]. The patient was a 14-year-old boy with prolonged QT interval, dysmorphic facial features (round face, flat nose, and low-set ear), and intellectual disability that was diagnosed as ASD at age 12. Functional studies of the mutant channel using HEK cells exhibited inward $\mathrm{Ca}^{2+}$ currents during step depolarizations whose voltage-dependent activation was markedly leftward shifted [68]. Peak current amplitude was significantly reduced and fast inactivation was markedly attenuated. Given that the inactivation gating changes persisted when $\mathrm{Ca}^{2+}$ was replaced with $\mathrm{Ba}^{2+}$, it was concluded that the S436F mutant altered preferentially the VDI of Cav1.2 channels. In conclusion, it is evident from the positions of the three mutations causing atypical TS that the regions of CACNA1C mainly involved in the autistic forms of TS are amino acid located at the far end of three S6 segments and the S4-S5 linker that line the inner vestibule of the pore [92]. These domains of the $\alpha 1$-subunit control Cav1.2 channel activation and inactivation; thus, critical mutations in these regions shift toward more negative potentials the activation of Cav1.2 channels and prolong the coupled VDI of the channel [89].

\section{CACNA 1 CACNA1C 1 is not small $C$ channelopathies causing long OT but not TS: indications for specific Cav1.2 Cav1.2 1.2 same size as $\mathrm{C}$ domains inducing autism}

Surprisingly, GOF mutations in Cav1.2 channels were for a long time exclusively linked to TS $[1,4,13,33,67,75,86,87]$. GOF mutations in CACNA1C started to be identified following WES in cohorts of familial LQTS without extracardiac symptoms $[15,36]$. P857R was the first gain-of-function mutation discovered in the conserved PEST domain (the Pro, Glu, Ser, Thr motif) of the Cav1.2 II-III linker (Fig. 2). Compared with the presently known TS mutations, the new GOF mutation was located in an unusual domain: the IIIII linker. When functionally expressed in HEK293 cells, it was evident that the P857R-induced GOF effects derived from an increased surface expression and not from an altered activation and inactivation gating of the mutant channel. The P857R appeared as an atypical GOF mutation unrelated to TS. A year later, Fukuyama et al. [36] described two other Cav1.2 gain-of-function mutations associated with LQT8: A582D and R858H. When expressed in Chinese hamster ovary (CHO) cells, the A582D mutant caused a significant slowing of fast inactivation, while the $\mathrm{R} 858 \mathrm{H}$ mutant increased the peak current density by $50 \%$. Unfortunately, the extent of SSI that is affected in TS mutants was not 
analyzed for the two mutations so that their effects could not be compared with those causing TS (Fig. 2).

In a more recent study, four GOF mutations not causing TS, but able to induce solitary long QT syndromes, were described in CACNA1C [98]. When expressed in Xenopus oocytes, two mutations (A28T and I1166V) caused increased $\mathrm{Ba}^{2+}$ current amplitudes, very little changes to the voltage dependence of channel activation but substantially reduced VDI for A28T. SSI was either weakly (I1166V) or markedly (A28T) positively shifted with little changes to the voltage dependence of activation with respect to WT channels; it was concluded that the two GOF mutations were able to cause a prolongation of in silico simulated ventricular APs, though their phenotypes were significantly different from those causing TS. Significantly different were the effects of the two other mutations (I1475M and E1496K) which produced gating effects impressively similar to TS: a leftward shift of the voltage dependence of activation, reduced VDI (particularly for the E1496K mutant), and incomplete SSI at very positive potentials $(+40 \mathrm{mV})$, strongly resembling those characteristics of the TS1 and TS2 G406R mutation causing autism. These data are of key importance. They suggest that activation-inactivation gating changes causing GOF in mutated Cav1.2 channels are not the only parameters that uniquely set the conditions for the development of ASD. Development of ASD requires GOF mutations located at specific sites, i.e., close to one of the four S6 segments, as in the case of the G406R mutation located in IS6, I1166 in IIIS6 and A1473G in IVS6 (Fig. 2).

Cav1.2 Cav1.2 LOF mutations L-type $\mathrm{Ca}^{2+}$ channel genes do not undergo only GOF mutations but may as well exhibit LOF mutations with associated short QT intervals that are responsible for the Brugada syndrome $(\mathrm{BrS})$. In a screening study of $82 \mathrm{BrS}$ patients, several mutations in $C A C N A 1 C$ and $C A C N B 2$ have been identified [2]. Two of the BrS probands had substitutions in $C A C N A 1 \mathrm{C}$ leading to A39V or G490R mutations in Cav1.2 and one patient with the mutation S481L in Cav $\beta 2 \mathrm{~b}$. All three mutations produced dramatic LOF of $\mathrm{Ca}^{2+}$ currents that could result from changes in channel gating, permeation, or trafficking. For a more detailed description on the CACNA1C mutations causing $\mathrm{BrS}$, see reference (12).

\section{New emerging views from the TS 2 TS2 2 is not small - neo mouse model}

About 10 years ago, Glenna Bett and Randal Rasmusson at Buffalo University generated heterozygous mice with the G406R mutation on exon 8 and an inverted neomycin cassette in exon 8A (TS2-neo) to allow the animal to survive through adulthood. These animals exhibited impaired social interaction and 
vocalization, and restricted and repetitive/perseverative behavior that are key features reminiscent of ASD [4] (see also [49, 77] for validation). The TS2-neo mouse is autistic without any cardiac abnormalities and is thus suitable to investigate mechanisms underlying ASD in which the molecular and cellular functions are affected by dysfunctional Cav1.2 channel gating [11].

Several recent papers have used the TS2-neo mouse to investigate the role of Cav1.2 calcium signaling in atypical brain development at molecular, cellular, and brain region levels as it is, without removing the protective neo-cassette. The TS2-neo mouse shows enhanced serotonin levels and axon innervation of the dorsal striatum suggesting that the ascending serotonin system is altered by Cav1.2 channels, as it occurs in several other ASD mouse models [29].

Stercobilin is dramatically reduced in fecal samples of TS2-neo mice [81], in line with observations of diverse microbiome metabolism in humans with ASD and with the idea that stercobilin may be used as a biomarker for ASD [25]. Impaired Cav1.2 channel gating was also observed to significantly enhance performance on an auditory processing task in TS2-neo mice [77], in good agreement with the enhanced low level perceptual discrimination for auditory stimuli observed in individuals with ASD [67]. TS2-neo mice have been used also to study how G406R-mutated channels alter the activity-dependent dendrite retraction induced by long-lasting $\mathrm{KCl}$ depolarizations in mouse cortical neurons [51]. Dendrite retraction appears independent of $\mathrm{Ca}^{2+}$ permeation through the mutant channel and is activated by the RhoA signaling cascade through the down regulation of the small $\mathrm{G}$ protein Gem bound to $\beta$-subunits. This study represents the first evidence that TS signaling may proceed independently of $\mathrm{Ca}^{2+}$ influx. In other words, simply through conformational changes of mutated Cav1.2 channels that trigger a cascade of protein-protein interactions (see [83]. The TS2 mouse model has been used also to study how oligodendrocyte progenitor cells (OPCs) isolated from the cortex of TS2-neo mice trigger process formation and promote oligodendrocyte-neuron interaction via the activation of CaMKII [24]. OPC development and oligodendrocyte myelination is enhanced in the brain of TS2-neo mice, suggesting that this mouse model is a useful tool to explore the role of Cav1.2 channels in axon myelination.

Increased window $\mathrm{Ca}^{2+}$ currents in chromaffin cells of TS2 TS2 2 of the same size of TS -neo mice The TS2-neo mouse has also been used recently to investigate how the Cav1.2 G406R mutation on exon 8 alters the excitability and secretory activity of adrenal chromaffin cells [20]. Mouse chromaffin cells (MCCs) express high densities of Cav1.2 and Cav1.3 L-type channels and are considered an excellent "neuron-like" cell model to study Cav channel function under a variety of physiological stimulations $[21,54]$. The study is also of clinical interest since the case report of a 2-month-old TS patient whose post- 
mortem autopsy revealed bilateral adrenal gland dystrophy due to a marked shrinkage and severe fibrosis of the medulla, most likely associated with an increased basal $\mathrm{Ca}^{2+}$ influx associated with the Cav1.2 G406R mutation [50].

Besides furnishing a valid explanation of the clinical case, our work [20] also offers a realistic view of how much the TS mutation alters native Cav1.2 channel currents, which normally represent a variable fraction (20 to 50\%) of the total $\mathrm{Ca}^{2+}$ currents driving neuronal activity. Pharmacologically isolated L-type currents in TS2-neo MCCs exhibit the typical voltage dependence and time course associated with the Cav1.2 TS-mutated channel reconstituted in heterologous expression systems $[8,28,87,101]$, i.e., slower inactivation, leftward shifted voltage-dependent activation, and steady-state inactivation (SSI) (Fig. 3). Compared with the gating changes observed in heterologous expression systems, the negative voltage shift of Cav1 channel activation and the slowing of the voltage-dependent inactivation (VDI) were quite attenuated (Fig. 3b, c). This is because Cav1.2 channels contribute only to $50 \%$ of the total L-type currents $[54,60,96]$, and exon 8 and exon $8 \mathrm{~A}$ are equally expressed in MCCs due to the protective effect of the inverted neo-cassette on exon 8A (see Fig. 2 in [20]).

\section{Fig. 3}

Voltage dependence of activation and steady-state inactivation (SSI) of L-type currents are "left shifted," and inactivation is slowed-down in TS2-neo-mutated adrenal MCCs. a Two sets of pharmacologically isolated L-type $\mathrm{Ca}^{2+}$ currents evoked by depolarizing pulses of $20 \mathrm{~ms}$ from -40 to $+10 \mathrm{mV}$ in step of $10 \mathrm{mV}$ from a WT and TS2-neo MCC in $2 \mathrm{mM} \mathrm{Ca}^{2+}$ (modified from ref. (20)). b Normalized L-type $\mathrm{Ca}^{2+}$ channel conductance, $g_{\mathrm{Ca}}(\mathrm{V})$, for WT (black line) and TS2-neo MCCs (red line) calculated from $g_{\mathrm{Ca}}(\mathrm{V})=I_{\mathrm{Ca}} /\left(V-E_{\mathrm{Ca}}\right)$ with $E_{\mathrm{Ca}}=+$ $60 \mathrm{mV}$. It is evident the negative shift of $g_{\mathrm{Ca}}(\mathrm{V})$ (for details see fig. 4 in ref. (20)). c Mean normalized L-type $\mathrm{Ca}^{2+}$ currents evoked by $1 \mathrm{~s}$ depolarizing pulses to + $10 \mathrm{mV}$ (left) for WT and TS2-neo MCCs. In the two mean traces are evident the fast (CDI) and slowly inactivating (VDI) components of L-type $\mathrm{Ca}^{2+}$ currents (modified from ref. (20)). d SSI(V) curves for WT (black squares) and TS2-neo (red circles) MCCs. The two continuous curves are the results of a curve fit with two Boltzmann equations (for details see fig. 5 in ref. (20)) 


\section{Adrenal chromaffin cells}

a

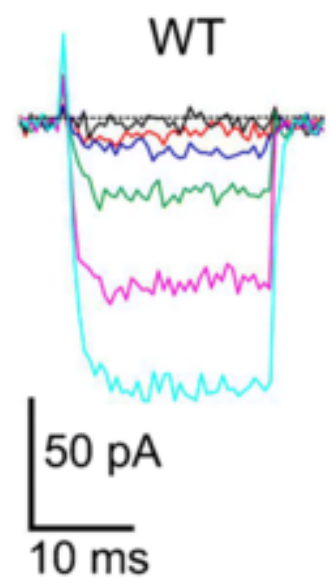

b
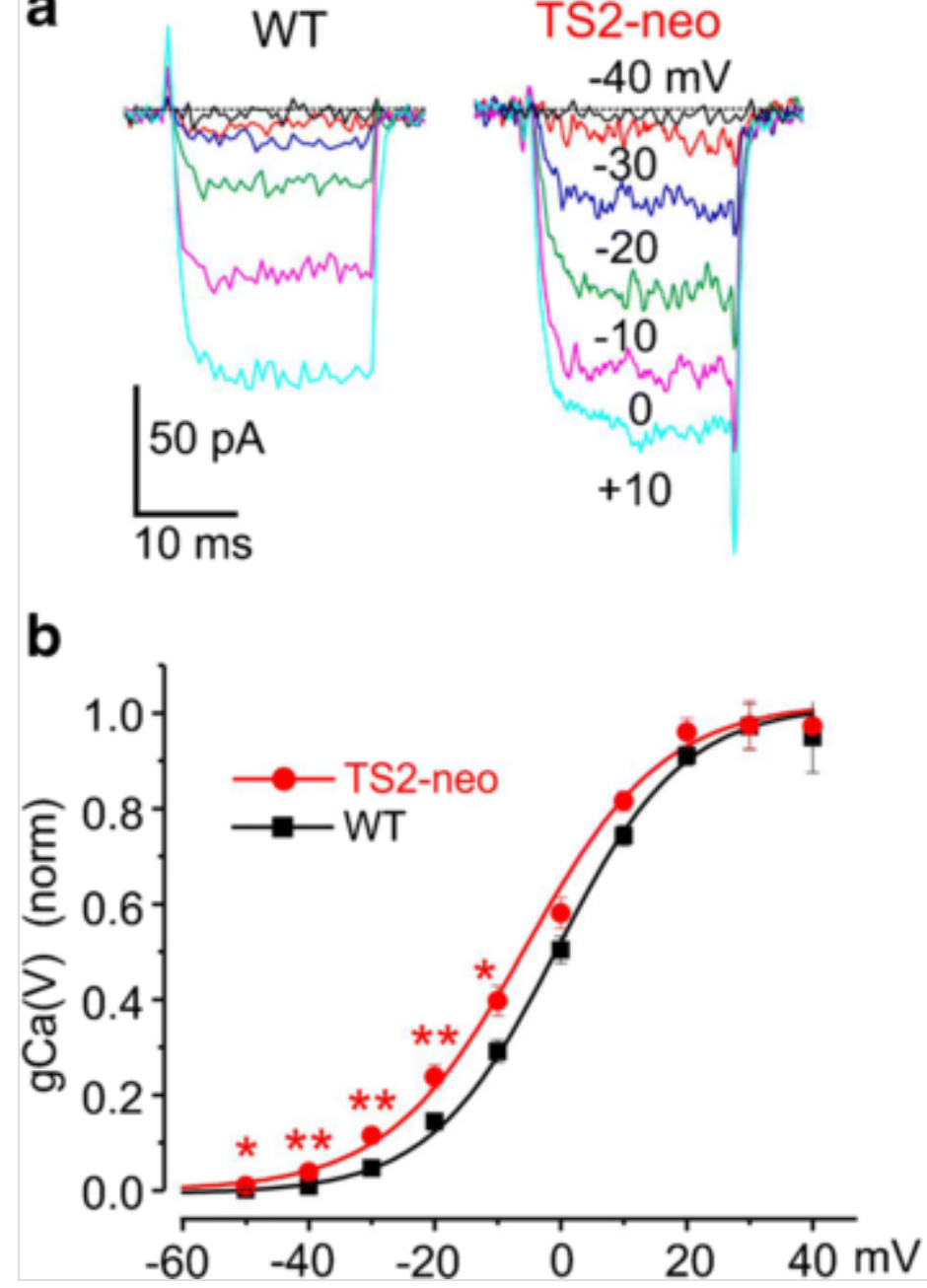

C

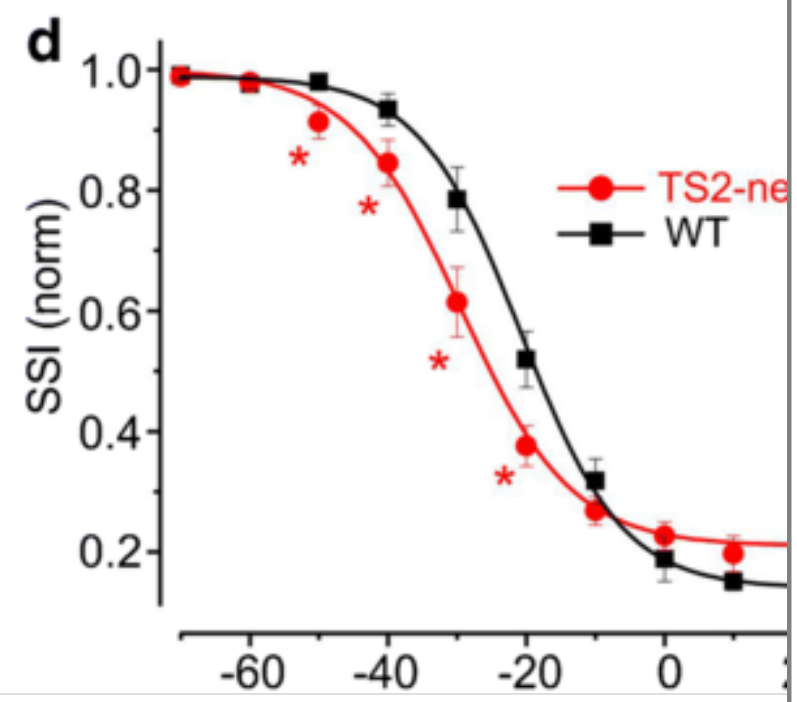

Of great interest here is the negative shift of the voltage-dependent activation and SSI of TS2-mutated L-type currents (Fig. 3b, d) that gave rise to a markedly increased "window $\mathrm{Ca}^{2+}$ current" that could steadily drive $\mathrm{Ca}^{2+}$ inside the cell near resting potential. As shown in Fig. 4, the "window $\mathrm{Ca}^{2+}$ current" for WTand TS2-mutated channels is calculated by multiplying the SSI(V) (Fig. 3d) with $g_{\mathrm{Ca}}(\mathrm{V})$ (Fig. 3b) to determine the probability of channel opening $\left(p_{\mathrm{o}}(\mathrm{V})\right)$. This latter, multiplied by the driving force $\left(V-E_{\mathrm{Ca}}\right)$, gives the window $\mathrm{Ca}^{2+}$ current $\left(I_{\mathrm{w}}\right)$. For the G406R TS2 mutant, this current is significantly larger and shifted to more negative voltages than for WT channels (shaded area at the bottom of Fig. 4). Notice that L-type channels (particularly Cav1.3) open at relatively low voltages in $2 \mathrm{mM} \mathrm{Ca}^{2+}$ in MCCs [57, 58], activate SK and BK potassium channels $[94,96]$, and contribute significantly to sustain spontaneous and evoked AP firing in cultured MCCs [56, 60]. Thus, a small continuous increase (over days) of the resting pacemaking current induced by the mistuned Cav1.2 channel gating triggers a number of $\mathrm{Ca}^{2+}$-dependent pathways that affect cell morphology and function [97]. As reported in our work, TS2-neo MCCs exhibited large areas of vacuolization and a reduced density of mitochondria that 
justified a visually evident cell swelling ( $\sim 24 \%$ of cell surface increase) and a markedly reduced mitochondrial metabolism. In addition, Nav channels density is drastically decreased, CCs undergo abnormal AP burst firing, and catecholamine release is markedly attenuated. This latter is most likely due to the cell swelling and modifications of the many structural elements that form the complex secretory apparatus regulating the priming, docking, and fusion of secretory granules [27]. Thus, taken all together, the TS2 mutation causes marked impairment of adrenal chromaffin cells excitability and exocytosis. Notice that a decreased density of Nav channels together with an increased inward $\mathrm{Ca}^{2+}$ influx boost MCCs to fire in burst and generate further $\mathrm{Ca}^{2+}$ entry $[21,41,95]$, thus sustaining high levels of intracellular $\mathrm{Ca}^{2+}$.

\section{Fig. 4}

The "window $\mathrm{Ca}^{2+}$ current" is markedly increased in TS2-neo-mutated MCCs. Ltype current inactivation window $\mathrm{Ca}^{2+}$ current $\left(I_{\mathrm{w}}\right)$ calculated from $\mathrm{SSI}(\mathrm{V})$ and $g_{\mathrm{Ca}}(\mathrm{V})$ of Fig. 3. $I_{\mathrm{w}}$ is obtained by multiplying the probability of channel opening $p_{\mathrm{o}}(\mathrm{V})$ by the driving force $\left(V-E_{\mathrm{Ca}}\right)$ with $E_{\mathrm{Ca}}=+60 \mathrm{mV}$ (continuous curves in bottom panel). The two $p_{\mathrm{o}}(\mathrm{V})$ curves are obtained by multiplying $\mathrm{SSI}(\mathrm{V})$ by $g_{\mathrm{Ca}}(\mathrm{V})$ (dotted curves in top panel). Notice the increased amplitude of $I_{\mathrm{w}}$ between -70 and $-40 \mathrm{mV}$ (shaded area) 


\section{Adrenal chromaffin cells}

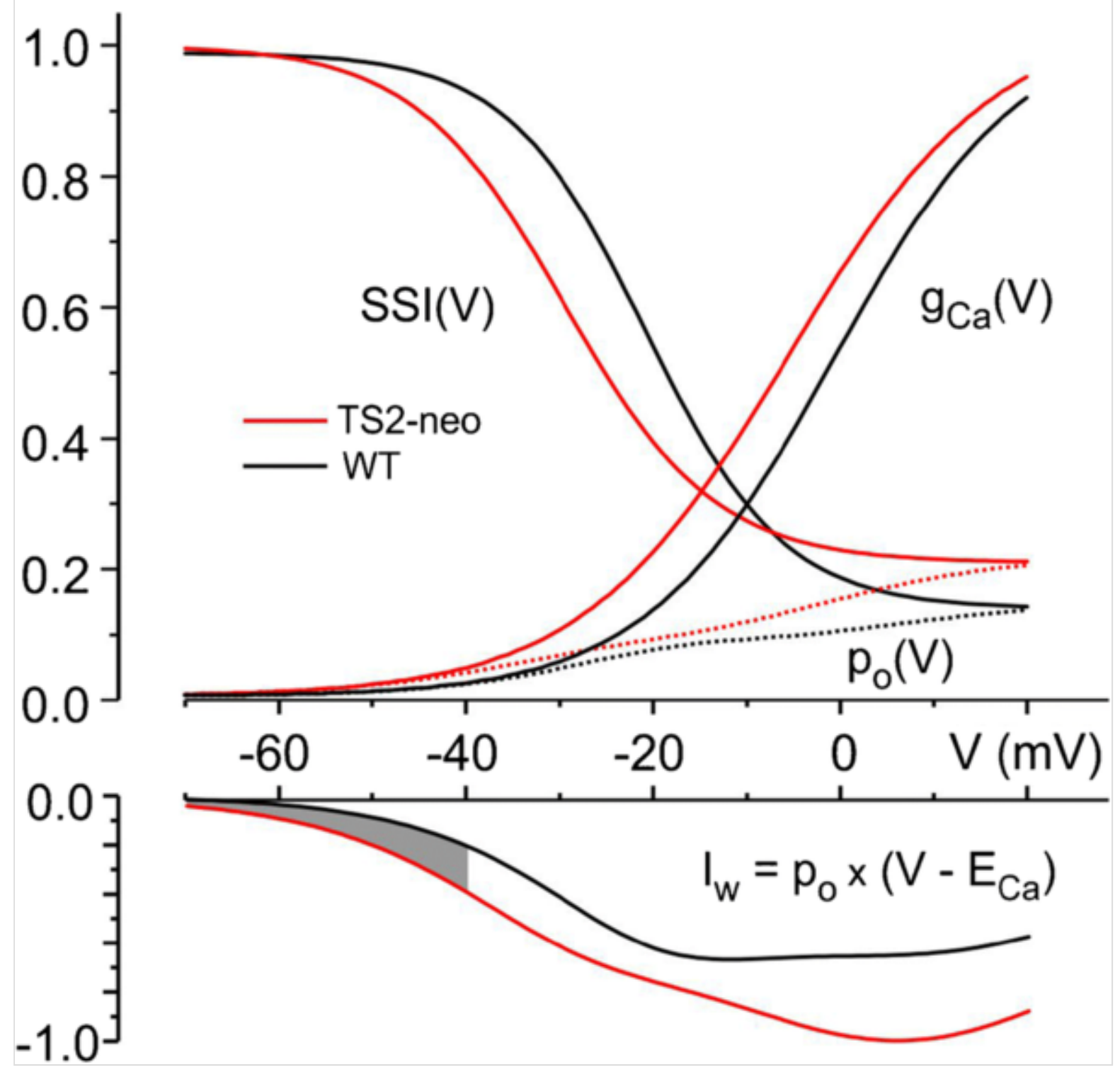

At present, there are no detailed finding characterizations for the excitability properties of in vitro cortical and hippocampal neurons induced by the TS2 mutation on endogenous Cav1.2 channels. Preliminary data from our group suggest that the same gating changes observed in the endogenous L-type channels of MCCs are evident in primary cultures of hippocampal neurons of mouse embryos [37, 38, 59, 79]. Figure 5a shows two examples of $\mathrm{Ca}^{2+}$ currents at $+10 \mathrm{mV}$ in $2 \mathrm{mM} \mathrm{Ca}^{2+}$ recorded from WT and TS2-neo hippocampal neurons during early days in culture (3-7 days in vitro, DIV), in control (black trace), and during application of $3 \mu \mathrm{M}$ nifedipine to fully block L-type channels (blue traces). The difference of the two currents (red traces), which represents the Ltype current component, shows that neuronal TS2-neo mutated L-type currents are more slowly inactivating than WT currents (Fig. 5b). This is confirmed by 
comparing the time course of $1 \mathrm{~s}$ averaged L-type currents from $n=6 \mathrm{WT}$ and $n=6$ TS2-neo mutated hippocampal neurons (Fig. 5c).

\section{Fig. 5}

L-type current inactivation is slower and less complete in TS2-mutated 3-7 DIV cultured hippocampal neurons. Hippocampal neurons were obtained from 18 days mouse embryos and grown in culture according to ref. (38). Recordings of $\mathrm{Ca}^{2+}$ currents were limited to cultured neurons of 3-7 DIV for two reasons: (1) they display short dendrites and recording is under the best conditions of voltage-clamp control, and (2) the effects are studied at the early days in culture where most of the cell reprogramming process takes place. $\mathbf{a ~ C a}^{2+}$ currents at $+10 \mathrm{mV}$ from $V_{\mathrm{h}}=$ $-80 \mathrm{mV}$ recorded in the whole-cell mode under control conditions in $2 \mathrm{mM} \mathrm{Ca}^{2+}$ (black traces) and during addition of $10 \mu \mathrm{M}$ nifedipine (blue traces) to block Ltype channels. The difference between the two traces (red traces) represents the time course of L-type current. The external solution contained (in $\mathrm{mM}$ ) $2 \mathrm{CaCl}_{2}$, $150 \mathrm{NaCl}, 1 \mathrm{MgCl}_{2}, 10$ glucose, and $10 \mathrm{HEPES}(\mathrm{pH}$ 7.4). Tetrodotoxin $(0.3 \mu \mathrm{M})$ was added to block Nav channels. The internal solution contained (in $\mathrm{mM}$ ) 90 CsCl, 20 TEACl, 10 EGTA, 10 glucose, $1 \mathrm{MgCl}_{2}, 4$ ATP, 0.5 GTP, and 15 phosphocreatine $(\mathrm{pH} 7.4)$ (see ref. $(5,6)$ ). b Overlapped L-type currents at + $10 \mathrm{mV}$ obtained from panel a. Notice the slower inactivating L-type current of TS2-neo mutated neuron. c Average time course of normalized L-type currents recorded during pulses of $1 \mathrm{~s}$ to $+10 \mathrm{mV}$ from $V_{\mathrm{h}}=-80 \mathrm{mV}$ from $n=6$ TS2mutated and $n=6$ WT hippocampal neurons 


\section{3-7 DIV hippocampal neurons}
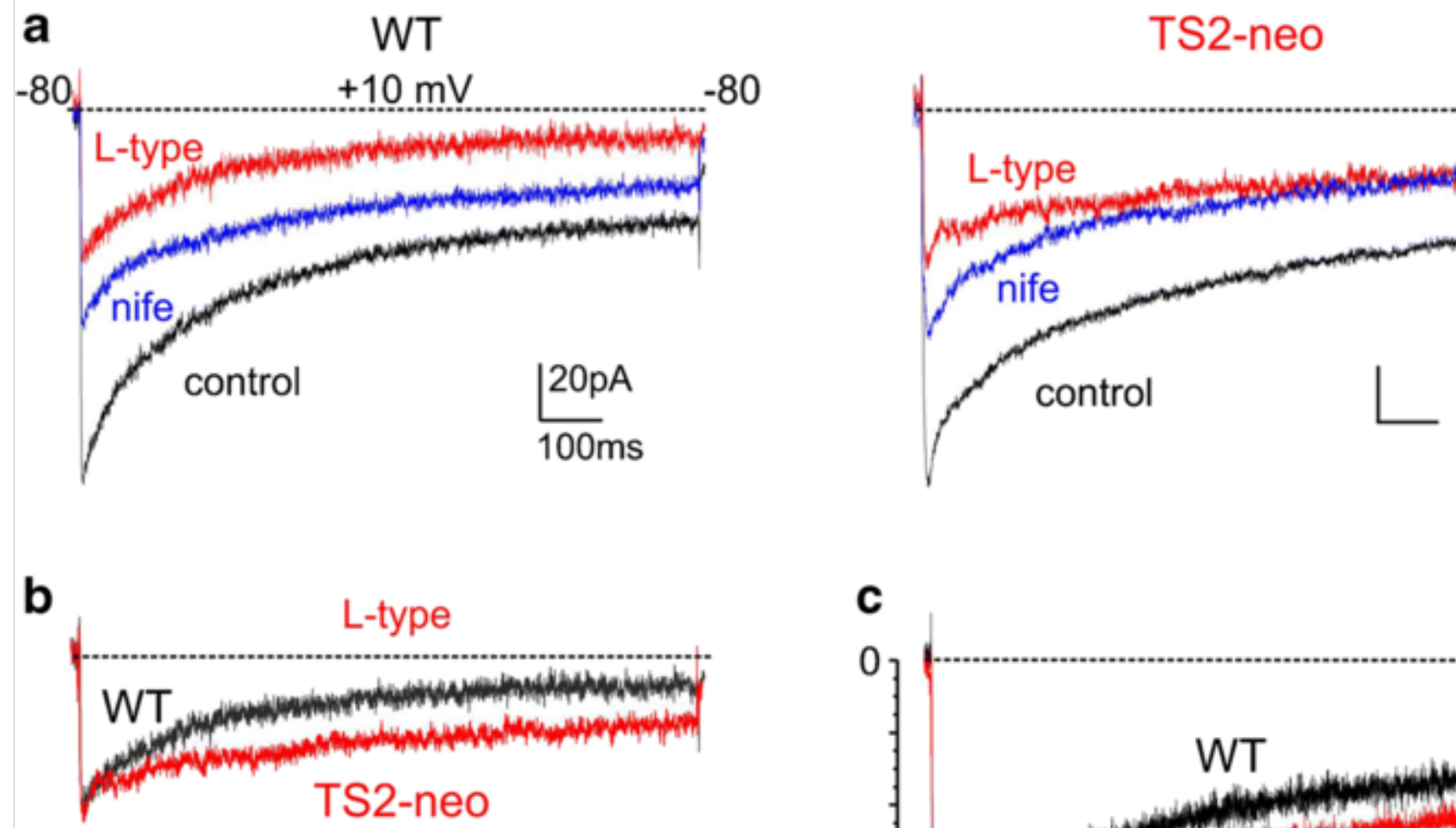

$$
\frac{20 \mathrm{pA}}{100 \mathrm{~ms}}
$$

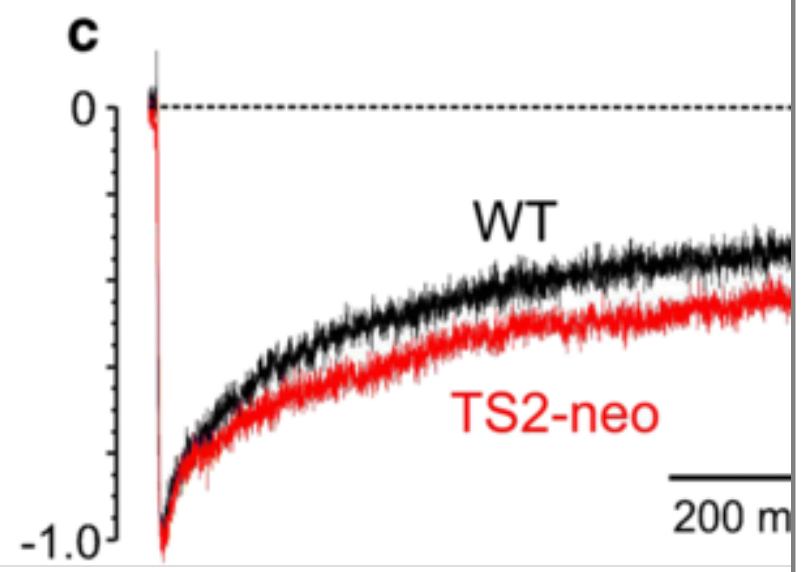

Taken together, all these findings suggest that hippocampal neurons of TS2-neo mice express Cav1.2-mutated channels with the expected phenotype of chromaffin cells and that the TS2-neo mouse is a promising animal model to investigate the pathophysiology of TS2-induced autism.

\section{Mistuned excitation-transcription coupling at the basis of TS-induced autism}

Cav1.2 channels are critical mediators of the activity-dependent gene expression that regulate synaptic and homeostatic plasticity [64, 99]. L-type channels convert the rapid firing of neurons into dynamic signals directed to the nucleus and play, as such, a key role in the regulation of neuronal E-T coupling [99]. Since the control of E-T coupling is critically important for long-term adaptive changes during neuronal development, specific Cav1.2 channels mistuning could drastically affect neuronal development and cause neuropsychiatric disorders such as schizophrenia, bipolar disorder, and ASD. Concerning the TS-induced form of autism, there is evidence now that the G406R mutation acts intracellularly by altering E-T signals through different intracellular pathways. 
They require either a $\mathrm{Ca}^{2+}$-flux independent cascade of events $[3,51,82,83]$ or a combination of $\mathrm{Ca}^{2+}$ ion influx and voltage-dependent conformational change of Cav1.2 channels (V $\Delta \mathrm{C})[52]$.

The " $\mathrm{Ca}^{2+}$ flux-independent" mechanism is based on the observation that G406R-mutated Cav1.2 channels favor the activity-dependent dendrite retraction induced by long-lasting not physiological depolarizations (1-9 h in $67 \mathrm{mM} \mathrm{KCl})$ in human iPSCs-derived cortical neurons [51]. Dendrite retraction occurs in the presence of $\mathrm{Ba}^{2+}$ and when mutant Cav1.2 channels are blocked by nimodipine proving that shortening of dendrites is independent of $\mathrm{Ca}^{2+}$-permeation through the L-type G406R mutant channel. The mechanism is triggered by the ectopic activation of the RhoA signaling cascade through the down regulation of the small RGK protein Gem that occurs due the weak binding of TS mutants to Gem. Loss of Gem, which is effectively bound to $\beta$-subunits in the AID domain of the I-II linker, increases the percentage of free $\beta$-subunits that could drive signals to the nucleus. It is important, however, that these interesting data are carefully evaluated in different neuronal preparations (see for instance [65]).

In line with the idea that TS signaling may simply proceed through $\mathrm{Ca}^{2+}$ fluxindependent conformational changes of mutated Cav1.2 channels are some recent findings showing that in HEK293 cells transfected with Cav1.2 $\alpha 1 / \beta 2 \mathrm{~b} /$ $\alpha 2 \delta$-subunits, membrane depolarization triggers the activation of c-Fos and MeCP2 via the Ras/ERK/CREB pathway [83]. The depolarization-induced c-Fos and $\mathrm{MeCP} 2$ activation occurs regardless of $\mathrm{Ca}^{2+}$ permeation through the channels but is strictly dependent on the presence of intracellular $\beta 2$ subunit. Both mutated G406R and G402S isoforms mediate E-T coupling through the Ras/ERK/CREB pathway. However, due to the leftward voltage shift of channel activation, only the autism-associated G406R mutant exhibits a depolarizationindependent CREB phosphorylation and spontaneous transcription of $\mathrm{cFos}$ and $\mathrm{MeCP} 2$ [84]. In conclusion, the enhanced G406R mutant activity at rest is sufficient to account for the increased basal transcriptional activation and dysregulated gene activity that may lead to autism.

Li et al. [52] have recently proposed an alternative ET coupling based on the sequential occurrence of two events. $\mathrm{Ca}^{2+}$ influx first mobilizes actin-bound CaMKII, freeing and subsequently accumulating the enzyme with calcineurin through a voltage-dependent conformational change (V $\Delta \mathrm{C})$-mediated mechanism. Neither signal alone $\left(\mathrm{Ca}^{2+}\right.$ influx and $\left.\mathrm{V} \Delta \mathrm{C}\right)$ is sufficient to activate ET coupling nor can signal order be inverted. Using primary cultures of cortical and hippocampal neurons transfected with fused Cav1.2 to an ATP-gated, $\mathrm{Ca}^{2+}$ permeable, tandem-trimeric $\mathrm{P} 2 \mathrm{X} 2$ channel (ttP2X-CaV1.2 chimera), the authors could show that $\mathrm{Ca}^{2+}$ influx should anticipate $\mathrm{V} \Delta \mathrm{C}$ by 10 to $20 \mathrm{~s}$. $\mathrm{Ca}^{2+}$-mediated 
activation of $\beta$ CaMKII (or $\alpha / \beta C a M K I I$ heteromultimers) is a prerequisite for their subsequent $\mathrm{V} \Delta \mathrm{C}$-mediated accumulation at Cav1.2 channels and for downstream signaling to pCREB (possibly by shuttling $\mathrm{Ca}^{2+} / \mathrm{CaM}$ to the nucleus via $\gamma$ CaMKII (see ref. (55)). Interestingly, under conditions of fixed $\mathrm{Ca}^{2+}$ fluxes, TS G406R mutant in the Cav1.2 portion of the fused ttP2X chimera exhibited gain-of-function $\mathrm{V} \Delta \mathrm{C}$ signaling. The $\alpha / \beta \mathrm{CaMKII}$ and CREB signaling increased by $\sim 30$ to $70 \%$, while the TS G402S mutant had nearly no effect, confirming that mistuning of $\mathrm{V} \Delta \mathrm{C}$ is associated with the G406R but not with the G402S mutant of TS, in correlation with the observed autistic symptoms in TS2 individuals.

\section{Conclusions and perspectives}

Conclusions As discussed in this review, the work of many groups in the last 15 years has allowed collecting an impressive amount of data that lead to some preliminary conclusion about the molecular and cellular events associated with the Cav1.2 GOF mutations leading to the autistic form of typical $[86,87]$ and atypical TS [42]. A first conclusion is that the slowing of inactivation gating that causes increased $\mathrm{Ca}^{2+}$ entry in TS-mutated neurons may contribute, but is unlikely the parameter that sets the conditions for changing neuronal firing and developing ASD. Autism is absent in TS2 patients bearing the G402S mutation on exon 8 , despite the mutation induces delayed Cav1.2 channel inactivation. A second conclusion is that the "leftward shifts" of the activation and SSI gatings of Cav1.2 mutants are not the only parameters that trigger the autistic forms of TS. Development of ASD requires GOF mutations with the "left-shifts" but needs to be located at specific sites, i.e., close to one of the four S6 segments of Cav1.2 channels, as in the case of the G406R mutation located in IS6. A third conclusion is that increased $\mathrm{Ca}^{2+}$ entry associated with Cav1.2 TS-variants is not the only mechanism required to trigger morphological and functional changes to TS-mistuned neurons, possibly causing autism [51, 69]. TS-induced conformational changes, either directly associated with the $\alpha 1$-subunit [52] or to cytoplasmic $\beta$-subunits of Cav1.2 channels $[83,84]$, are also required to regulate the excitation-transcription coupling to the nucleus that possibly leads to developmental neuronal dysfunction. A final conclusion concerns the different approaches used to study the mechanisms underlying ASD in TS patients. Among the various, the use of TS2-neo KI mouse (or any newly designed TS mouse model) and iPSC-derived neurons from TS patients appears undoubtedly the most promising.

Perspectives iPSC-derived neurons will certainly help to progress in identifying mistuned neuronal excitability, synaptic plasticity, and specific intracellular pathways of ASD-related proteins associated with the altered 
excitation-transcription coupling controlling the expression of ASD-related genes in TS-mutated neurons (see ref. (63) for a recent review). However, unquestionably, the most promising advancement is expected from a wider use of the available TS2-neo mouse model. Presently, there is an impressive lack of information about the mistuned function of single neuron excitability, synaptogenesis, and AP firing both in reconstituted neuronal microcircuits and in in vitro brain areas, which demands for a common multidisciplinary effort to investigate TS-altered neurons to reach viable pathophysiological hypothesis on how Cav1.2 TS mutants generate autism. Nothing is known on how excitatory pyramidal neurons and inhibitory GABAergic interneurons change their spontaneous and current-evoked mode of firing (tonic vs. bursts). It is still undetermined whether the number of functioning neurons forming spontaneously active microcircuits increases or decreases in TS-mutated neurons and if the length and number of dendrites is retracted in an activity-dependent manner using physiological stimulations, such as trains of AP. Not last, it would be important to know how the excitatory (E) and inhibitory (I) synapses alter their strength (RRP, probability of vesicle release, quantal size) and how the E/I balance of cultured neuronal networks and brain slices changes during development in TS-mutated neurons.

A final great advantage of using mouse models of monogenic ASD is the possibility of attempting a pharmacological treatment to ameliorate ASD-like behavior. In the case of TS, since the symptoms are associated with a Cav1.2 channel GOF, L-type $\mathrm{Ca}^{2+}$ channel blockers are the most promising and immediate therapeutic option. At the light of the present findings, however, the search from new " $\mathrm{Ca}^{2+}$ channel modulators" able to shift back the voltagedependent activation of Cav1.2-mutated channels without blocking the channel should also be boosted. Drugs causing a "positive shift" of Cav1.2 channel activation would specifically act on the increased window $\mathrm{Ca}^{2+}$ current at rest, without reducing $\mathrm{Ca}^{2+}$ fluxes during cell activity (tonic or burst firings), as classical L-type channel blockers do. This will preserve intact activity-dependent $\mathrm{Ca}^{2+}$ signalings in developing neurons.

\section{Publisher's note}

Springer Nature remains neutral with regard to jurisdictional claims in published maps and institutional affiliations.

\section{Funding information}

This work was supported by the Telethon Foundation (grant no.GGP15110) to E.C. 


\section{References}

1. Almagor L, Chomsky-Hecht O, Ben-Mocha A, Hendin-Barak D, Dascal N, Hirsch JA (2012) Ca(V)1.2 I-II linker structure and Timothy syndrome. Channels (Austin) 6:468-472

2. Antzelevitch C, Pollevick GD, Cordeiro JM, Casis O, Sanguinetti MC, Aizawa Y, Guerchicoff A, Pfeiffer R, Oliva A, Wollnik B, Gelber P, Bonaros EP Jr, Burashnikov E, Wu Y, Sargent JD, Schickel S, Oberheiden R, Bhatia A, Hsu LF, Haïssaguerre M, Schimpf R, Borggrefe M, Wolpert C (2007) Loss-of-function mutations in the cardiac calcium channel underlie a new clinical entity characterized by ST-segment elevation, short QT intervals, and sudden cardiac death. Circulation 115:442-449

3. Atlas D (2013) The voltage-gated calcium channel functions as the molecular switch of synaptic transmission. Annu Rev Biochem 82:607-635

4. Bader PL, Faizi M, Kim LH, Owen SF, Tadross MR, Alfa RW, Bett GC, Tsien RW, Rasmusson RL, Shamloo M (2011) Mouse model of Timothy syndrome recapitulates triad of autistic traits. Proc Natl Acad Sci U S A 108:15432-15437

5. Baldelli P, Forni PE, Carbone E (2000) BDNF, NT-3 and NGF induce distinct new $\mathrm{Ca} 2+$ channel synthesis in developing hippocampal neurons. Eur J Neurosci 12:4017-4032

6. Baldelli P, Hernandez-Guijo JM, Carabelli V, Carbone E (2005) Brainderived neurotrophic factor enhances GABA release probability and nonuniform distribution of $\mathrm{N}$ - and P/Q-type channels on release sites of hippocampal inhibitory synapses. J Neurosci 25:3358-3368

7. Barnabei VM, Rasmusson RL, Bett GC (2014) Autism and induced labor: is calcium a potential mechanistic link? Am J Obstet Gynecol 210:494-495

8. Barrett CF, Tsien RW (2008) The Timothy syndrome mutation differentially affects voltage- and calcium-dependent inactivation of CaV1.2 L-type calcium channels. Proc Natl Acad Sci U S A 105:2157-2162

9. Berger SM, Bartsch D (2014) The role of L-type voltage-gated calcium channels Cav1.2 and Cav1.3 in normal and pathological brain function. Cell Tissue Res 357:463-476 
10. Bett GC, Kaplan AD, Lis A, Cimato TR, Tzanakakis ES, Zhou Q, Morales MJ, Rasmusson RL (2013) Electronic "expression" of the inward rectifier in cardiocytes derived from human-induced pluripotent stem cells. Heart Rhythm 10:1903-1910

11. Bett GC, Lis A, Wersinger SR, Baizer JS, Duffey ME, Rasmusson RL (2012) A mouse model of Timothy syndrome: a complex autistic disorder resulting from a point mutation in Cav1.2. N Am J Med Sci 5:135-140

12. Betzenhauser MJ, Pitt GS, Antzelevitch C (2015) Calcium channel mutations in cardiac arrhythmia syndromes. Curr Mol Pharmacol 8:133-142

13. Bhat S, Dao DT, Terrillion CE, Arad M, Smith RJ, Soldatov NM, Gould TD (2012) CACNA1C (Cav1.2) in the pathophysiology of psychiatric disease. Prog Neurobiol 99:1-14

14. Bidaud I, Lory P (2011) Hallmarks of the channelopathies associated with L-type calcium channels: a focus on the Timothy mutations in $\mathrm{Ca}(\mathrm{v}) 1.2$ channels. Biochimie 93:2080-2086

15. Boczek NJ, Best JM, Tester DJ, Giudicessi JR, Middha S, Evans JM, Kamp TJ, Ackerman MJ (2013) Exome sequencing and systems biology converge to identify novel mutations in the L-type calcium channel, CACNA1C, linked to autosomal dominant long QT syndrome. Circ Cardiovasc Genet 6:279-289

16. Boczek NJ, Miller EM, Ye D, Nesterenko VV, Tester DJ, Antzelevitch C, Czosek RJ, Ackerman MJ, Ware SM (2015) Novel Timothy syndrome mutation leading to increase in CACNA1C window current. Heart Rhythm $12: 211-219$

17. Breitenkamp AF, Matthes J, Nass RD, Sinzig J, Lehmkuhl G, Nurnberg P, Herzig S (2014) Rare mutations of CACNB2 found in autism spectrum disease-affected families alter calcium channel function. PLoS One 9:e95579

18. Buraei Z, Yang J (2010) The $\beta$ subunit of voltage-gated Ca2+ channels. Physiol Rev 90:1461-1506

19. Buraei Z, Yang J (2013) Structure and function of the beta subunit of voltage-gated $\mathrm{Ca}(2)(+)$ channels. Biochim Biophys Acta 1828:1530-1540 
20. Calorio C, Gavello D, Guarina L, Salio C, Sassoe-Pognetto M, Riganti C, Bianchi FT, Hofer NT, Tuluc P, Obermair GJ, Defilippi P, Balzac F, Turco E, Bett GC, Rasmusson RL, Carbone E (2019) Impaired chromaffin cell excitability and exocytosis in autistic Timothy syndrome TS2-neo mouse rescued by L-type calcium channel blockers. J Physiol Lond 597:1705-1733

21. Carbone E, Borges R, Eiden LE, Garcia AG, Hernandez-Cruz A (2019) Chromaffin cells of the adrenal medulla: physiology, pharmacology, and disease. Compr Physiol 9:1443-1502

22. Catterall WA (1995) Structure and function of voltage-gated ion channels. Annu Rev Biochem 64:493-531

23. Catterall WA (2011) Voltage-gated calcium channels. Cold Spring Harb Perspect Biol 3:23

24. Cheli VT, Santiago González DA, Zamora NN, Lama TN, Spreuer V, Rasmusson RL, Bett GC, Panagiotakos G, Paez PM (2018) Enhanced oligodendrocyte maturation and myelination in a mouse model of Timothy syndrome. Glia 66:2324-2339

25. Coffey JM, Vadas AJ, Puleo TR, Lewis KP, Pirrone GF, Rudolph HL, Helms ED, Wood TD, Flynn-Charlebois A (2018) Synthesis and characterization of a deuterium labeled stercobilin: a potential biomarker for autism. J Label Compd Radiopharm 61:742-748

26. De Waard M, Pragnell M, Campbell KP (1994) Ca2+ channel regulation by a conserved beta subunit domain. Neuron 13:495-503

27. Dhara M, Mohrmann R, Bruns D (2018) v-SNARE function in chromaffin cells. Pflugers Arch - Eur J Physiol 470:169-180

28. Dick IE, Joshi-Mukherjee R, Yang W, Yue DT (2016) Arrhythmogenesis in Timothy syndrome is associated with defects in $\mathrm{Ca}(2+)$-dependent inactivation. Nat Commun 7:10370

29. Ehlinger DG, Commons KG (2017) Altered Cav1.2 function in the Timothy syndrome mouse model produces ascending serotonergic abnormalities. Eur J Neurosci 46:2416-2425

30. Ertel EA, Campbell KP, Harpold MM, Hofmann F, Mori Y, Perez-Reyes E, Schwartz A, Snutch TP, Tanabe T, Birnbaumer L, Tsien RW, Catterall WA 
31. Erxleben C, Liao Y, Gentile S, Chin D, Gomez-Alegria C, Mori Y, Birnbaumer L, Armstrong DL (2006) Cyclosporin and Timothy syndrome increase mode 2 gating of CaV1.2 calcium channels through aberrant phosphorylation of S6 helices. Proc Natl Acad Sci U S A 103:3932-3937

32. Etemad S, Obermair GJ, Bindreither D, Benedetti A, Stanika R, Di Biase V, Burtscher V, Koschak A, Kofler R, Geley S, Wille A, Lusser A, Flockerzi V, Flucher BE (2014) Differential neuronal targeting of a new and two known calcium channel $\beta 4$ subunit splice variants correlates with their regulation of gene expression. J Neurosci 34:1446-1461

33. Etheridge SP, Bowles NE, Arrington CB, Pilcher T, Rope A, Wilde AA, Alders M, Saarel EV, Tavernier R, Timothy KW, Tristani-Firouzi M (2011) Somatic mosaicism contributes to phenotypic variation in Timothy syndrome. Am J Med Genet A 155a:2578-2583

34. Ferreira MAR, O’Donovan MC, Meng YA, Jones IR, Ruderfer DM, Jones L, Fan J, Kirov G, Perlis RH, Green EK, Smoller JW, Grozeva D, Stone J, Nikolov I, Chambert K, Hamshere ML, Nimgaonkar VL, Moskvina V, Thase ME, Caesar S, Sachs GS, Franklin J, Gordon-Smith K, Ardlie KG, Gabriel SB, Fraser C, Blumenstiel B, Defelice M, Breen G, Gill M, Morris DW, Elkin A, Muir WJ, McGhee KA, Williamson R, MacIntyre DJ, MacLean AW, Clair DS, Robinson M, Van Beck M, Pereira ACP, Kandaswamy R, McQuillin A, Collier DA, Bass NJ, Young AH, Lawrence J, Ferrier IN, Anjorin A, Farmer A, Curtis D, Scolnick EM, Mcguffin P, Daly MJ, Corvin AP, Holmans PA, Blackwood DH, Gurling HM, Owen MJ, Purcell SM, Sklar P, Craddock N, Wellcome Trust Case Control C (2008) Collaborative genome-wide association analysis supports a role for ANK3 and CACNA1C in bipolar disorder. Nat Genet 40:1056-1058

35. Frohler S, Kieslich M, Langnick C, Feldkamp M, Opgen-Rhein B, Berger F, Will JC, Chen W (2014) Exome sequencing helped the fine diagnosis of two siblings afflicted with atypical Timothy syndrome (TS2). BMC Med Genet 15:48

36. Fukuyama M, Wang Q, Kato K, Ohno S, Ding W-G, Toyoda F, Itoh H, Kimura H, Makiyama T, Ito M, Matsuura H, Horie M (2014) Long QT syndrome type 8: novel CACNA1C mutations causing QT prolongation and variant phenotypes. Europace 16:1828-1837 
37. Gavello D, Calorio C, Franchino C, Cesano F, Carabelli V, Carbone E, Marcantoni A (2018) Early alterations of hippocampal neuronal firing induced by Abeta42. Cereb Cortex 28:433-446

38. Gavello D, Rojo-Ruiz J, Marcantoni A, Franchino C, Carbone E, Carabelli V (2012) Leptin counteracts the hypoxia-induced inhibition of spontaneously firing hippocampal neurons: a microelectrode array study. PLoS One 7:e41530

39. Gillis J, Burashnikov E, Antzelevitch C, Blaser S, Gross G, Turner L, Babul-Hirji R, Chitayat D (2012) Long QT, syndactyly, joint contractures, stroke and novel CACNA1C mutation: expanding the spectrum of Timothy syndrome. Am J Med Genet A 158a:182-187

40. Green EK, Grozeva D, Jones I, Jones L, Kirov G, Caesar S, GordonSmith K, Fraser C, Forty L, Russell E, Hamshere ML, Moskvina V, Nikolov I, Farmer A, McGuffin P, Holmans PA, Owen MJ, O'Donovan MC, Craddock $\mathrm{N}$ (2010) The bipolar disorder risk allele at CACNA1C also confers risk of recurrent major depression and of schizophrenia. Mol Psychiatry 15:10161022

41. Guarina L, Vandael DH, Carabelli V, Carbone E (2017) Low pHo boosts burst firing and catecholamine release by blocking TASK-1 and BK channels while preserving Cav1 channels in mouse chromaffin cells. J Physiol 595:2587-2609

42. Han D, Xue X, Yan Y, Li G (2019) Highlight article: dysfunctional Cav1.2 channel in Timothy syndrome, from cell to bedside. Exp Biol Med (Maywood) 244:960-971

43. Hanlon MR, Berrow NS, Dolphin AC, Wallace BA (1999) Modelling of a voltage-dependent $\mathrm{Ca} 2+$ channel beta subunit as a basis for understanding its functional properties. FEBS Lett 445:366-370

44. Hering S, Zangerl-Plessl EM, Beyl S, Hohaus A, Andranovits S, Timin EN (2018) Calcium channel gating. Pflugers Arch - Eur J Physiol 470:12911309

45. Hiippala A, Tallila J, Myllykangas S, Koskenvuo JW, Alastalo TP (2015) Expanding the phenotype of Timothy syndrome type 2: an adolescent with ventricular fibrillation but normal development. Am J Med Genet A 167A:629-634 
46. Hofer NT, Tuluc P, Ortner NJ, Nikonishyna YV, Fernándes-Quintero ML, Liedl KR, Flucher BE, Cox H, Striessnig J (2020) Biophysical classification of a CACNA1D de novo mutation as a high-risk mutation for a severe neurodevelopmental disorder. Mol Autism 11:4-4

47. Hofmann F, Lacinová L, Klugbauer N (1999) Voltage-dependent calcium channels: from structure to function. Rev Physiol Biochem Pharmacol 139:33-87

48. Kabir ZD, Martinez-Rivera A, Rajadhyaksha AM (2017) From gene to behavior: L-type calcium channel mechanisms underlying neuropsychiatric symptoms. Neurotherapeutics 14:588-613

49. Kabitzke PA, Brunner D, He D, Fazio PA, Cox K, Sutphen J, Thiede L, Sabath E, Hanania T, Alexandrov V, Rasmusson R, Spooren W, Ghosh A, Feliciano P, Biemans B, Benedetti M, Clayton AL (2017) Comprehensive analysis of two Shank3 and the Cacna1c mouse models of autism spectrum disorder. Genes Brain Behav

50. Kawaida M, Abe T, Nakanishi T, Miyahara Y, Yamagishi H, Sakamoto M, Yamada T (2016) A case of Timothy syndrome with adrenal medullary dystrophy. Pathol Int 66:587-592

51. Krey JF, Pasca SP, Shcheglovitov A, Yazawa M, Schwemberger R, Rasmusson R, Dolmetsch RE (2013) Timothy syndrome is associated with activity-dependent dendritic retraction in rodent and human neurons. Nat Neurosci 16:201-209

52. Li B, Tadross MR, Tsien RW (2016) Sequential ionic and conformational signaling by calcium channels drives neuronal gene expression. Science (New York, NY) 351:863-867

53. Liao P, Soong TW (2010) CaV1.2 channelopathies: from arrhythmias to autism, bipolar disorder, and immunodeficiency. Pflugers Arch - Eur J Physiol 460:353-359

54. Lingle CJ, Martinez-Espinosa PL, Guarina L, Carbone E (2018) Roles of $\mathrm{Na}(+), \mathrm{Ca}(2+)$, and $\mathrm{K}(+)$ channels in the generation of repetitive firing and rhythmic bursting in adrenal chromaffin cells. Pflugers Arch - Eur J Physiol 470:39-52 
55. Ma H, Groth RD, Cohen SM, Emery JF, Li B, Hoedt E, Zhang G, Neubert TA, Tsien RW (2014) $\gamma$ CaMKII shuttles $\mathrm{Ca}^{2+} / \mathrm{CaM}$ to the nucleus to trigger CREB phosphorylation and gene expression. Cell 159:281-294

56. Mahapatra S, Marcantoni A, Vandael DHF, Striessnig J, Carbone E (2011) Are $\mathrm{Ca}(\mathrm{v}) 1.3$ pacemaker channels in chromaffin cells? Possible bias from resting cell conditions and DHP blockers usage. Channels 5:219-224

57. Marcantoni A, Baldelli P, Hernandez-Guijo JM, Comunanza V, Carabelli V, Carbone E (2007) L-type calcium channels in adrenal chromaffin cells: role in pace-making and secretion. Cell Calcium 42:397-408

58. Marcantoni A, Carabelli V, Vandael DH, Comunanza V, Carbone E (2009) PDE type-4 inhibition increases L-type Ca2+ currents, action potential firing, and quantal size of exocytosis in mouse chromaffin cells. Pflugers Arch - Eur J Physiol 457:1093-1110

59. Marcantoni A, Cerullo MS, Buxeda P, Tomagra G, Giustetto M, Chiantia G, Carabelli V, Carbone E (2020) Abeta42 oligomers up-regulate the excitatory synapses by potentiating presynaptic release while impairing postsynaptic NMDA receptors. J Physiol 598:2183-2197

60. Marcantoni A, Vandael DHF, Mahapatra S, Carabelli V, SinneggerBrauns MJ, Striessnig J, Carbone E (2010) Loss of Cav1.3 channels reveals the critical role of L-type and BK channel coupling in pacemaking mouse adrenal chromaffin cells. J Neurosci 30:491-504

61. Minor DL Jr, Findeisen F (2010) Progress in the structural understanding of voltage-gated calcium channel $(\mathrm{CaV})$ function and modulation. Channels (Austin) 4:459-474

62. Moon AL, Haan N, Wilkinson LS, Thomas KL, Hall J (2018) CACNA1C: association with psychiatric disorders, behavior, and neurogenesis. Schizophr Bull 44:958-965

63. Mullins C, Fishell G, Tsien RW (2016) Unifying views of autism spectrum disorders: a consideration of autoregulatory feedback loops. Neuron 89:1131-1156

64. Murphy TH, Worley PF, Baraban JM (1991) L-type voltage-sensitive calcium channels mediate synaptic activation of immediate early genes.

Neuron 7:625-635 
65. Nimmervoll B, Flucher BE, Obermair GJ (2013) Dominance of P/Q-type calcium channels in depolarization-induced presynaptic FM dye release in cultured hippocampal neurons. Neuroscience 253:330-340

66. Obermair GJ, Schlick B, Di Biase V, Subramanyam P, Gebhart M, Baumgartner S, Flucher BE (2010) Reciprocal interactions regulate targeting of calcium channel beta subunits and membrane expression of alpha1 subunits in cultured hippocampal neurons. J Biol Chem 285:5776-5791

67. Ouimet T, Foster NE, Tryfon A, Hyde KL (2012) Auditory-musical processing in autism spectrum disorders: a review of behavioral and brain imaging studies. Ann N Y Acad Sci 1252:325-331

68. Ozawa J, Ohno S, Saito H, Saitoh A, Matsuura H, Horie M (2018) A novel CACNA1C mutation identified in a patient with Timothy syndrome without syndactyly exerts both marked loss- and gain-of-function effects. HeartRhythm Case Rep 4:273-277

69. Panagiotakos G, Haveles C, Arjun A, Petrova R, Rana A, Portmann T, Paşca SP, Palmer TD, Dolmetsch RE (2019) Aberrant calcium channel splicing drives defects in cortical differentiation in Timothy syndrome. eLife 8:e51037

70. Pasca SP, Panagiotakos G, Dolmetsch RE (2014) Generating human neurons in vitro and using them to understand neuropsychiatric disease. Annu Rev Neurosci 37:479-501

71. Pasca SP, Portmann T, Voineagu I, Yazawa M, Shcheglovitov A, Pasca AM, Cord B, Palmer TD, Chikahisa S, Nishino S, Bernstein JA, Hallmayer J, Geschwind DH, Dolmetsch RE (2011) Using iPSC-derived neurons to uncover cellular phenotypes associated with Timothy syndrome. Nat Med 17:1657-U1176

72. Pinggera A, Lieb A, Benedetti B, Lampert M, Monteleone S, Liedl KR, Tuluc P, Striessnig J (2015) CACNA1D de novo mutations in autism spectrum disorders activate Cav1.3 L-type calcium channels. Biol Psychiatry $77: 816-822$

73. Pinggera A, Mackenroth L, Rump A, Schallner J, Beleggia F, Wollnik B, Striessnig J (2017) New gain-of-function mutation shows CACNA1D as recurrently mutated gene in autism spectrum disorders and epilepsy. Hum Mol Genet 26:2923-2932 
74. Pragnell M, De Waard M, Mori Y, Tanabe T, Snutch TP, Campbell KP (1994) Calcium channel beta-subunit binds to a conserved motif in the I-II cytoplasmic linker of the alpha 1-subunit. Nature 368:67-70

75. Ramachandran KV, Hennessey JA, Barnett AS, Yin X, Stadt HA, Foster E, Shah RA, Yazawa M, Dolmetsch RE, Kirby ML, Pitt GS (2013) Calcium influx through L-type CaV1.2 Ca2+ channels regulates mandibular development. J Clin Invest 123:1638-1646

76. Raybaud A, Dodier Y, Bissonnette P, Simoes M, Bichet DG, Sauve R, Parent L (2006) The role of the GX9GX3G motif in the gating of high voltage-activated Ca2+ channels. J Biol Chem 281:39424-39436

77. Rendall AR, Ford AL, Perrino PA, Holly FR (2017) Auditory processing enhancements in the TS2-neo mouse model of Timothy syndrome, a rare genetic disorder associated with autism spectrum disorders. Adv Neurodev Disord 1:176-189

78. Ripke S, O’Dushlaine C, Chambert K, Moran JL, Kähler AK, Akterin S, Bergen SE, Collins AL, Crowley JJ, Fromer M, Kim Y, Lee SH, Magnusson PK, Sanchez N, Stahl EA, Williams S, Wray NR, Xia K, Bettella F, Borglum AD, Bulik-Sullivan BK, Cormican P, Craddock N, de Leeuw C, Durmishi N, Gill M, Golimbet V, Hamshere ML, Holmans P, Hougaard DM, Kendler KS, Lin K, Morris DW, Mors O, Mortensen PB, Neale BM, O'Neill FA, Owen MJ, Milovancevic MP, Posthuma D, Powell J, Richards AL, Riley BP, Ruderfer D, Rujescu D, Sigurdsson E, Silagadze T, Smit AB, Stefansson H, Steinberg S, Suvisaari J, Tosato S, Verhage M, Walters JT, Levinson DF, Gejman PV, Kendler KS, Laurent C, Mowry BJ, O'Donovan MC, Owen MJ, Pulver AE, Riley BP, Schwab SG, Wildenauer DB, Dudbridge F, Holmans P, Shi J, Albus M, Alexander M, Campion D, Cohen D, Dikeos D, Duan J, Eichhammer P, Godard S, Hansen M, Lerer FB, Liang KY, Maier W, Mallet J, Nertney DA, Nestadt G, Norton N, O'Neill FA, Papadimitriou GN, Ribble R, Sanders AR, Silverman JM, Walsh D, Williams NM, Wormley B, Arranz MJ, Bakker S, Bender S, Bramon E, Collier D, Crespo-Facorro B, Hall J, Iyegbe C, Jablensky A, Kahn RS, Kalaydjieva L, Lawrie S, Lewis CM, Lin K, Linszen DH, Mata I, McIntosh A, Murray RM, Ophoff RA, Powell J, Rujescu D, Van Os J, Walshe M, Weisbrod M, Wiersma D, Donnelly P, Barroso I, Blackwell JM, Bramon E, Brown MA, Casas JP, Corvin AP, Deloukas P, Duncanson A, Jankowski J, Markus HS, Mathew CG, Palmer CN, Plomin R, Rautanen A, Sawcer SJ, Trembath RC, Viswanathan AC, Wood NW, Spencer CC, Band G, Bellenguez C, Freeman C, Hellenthal G, Giannoulatou E, Pirinen M, Pearson RD, Strange A, Su Z, Vukcevic D, Donnelly P, Langford 
C, Hunt SE, Edkins S, Gwilliam R, Blackburn H, Bumpstead SJ, Dronov S, Gillman M, Gray E, Hammond N, Jayakumar A, McCann OT, Liddle J, Potter SC, Ravindrarajah R, Ricketts M, Tashakkori-Ghanbaria A, Waller MJ, Weston P, Widaa S, Whittaker P, Barroso I, Deloukas P, Mathew CG, Blackwell JM, Brown MA, Corvin AP, MI MC, Spencer CC, Bramon E, Corvin AP, O'Donovan MC, Stefansson K, Scolnick E, Purcell S, McCarroll SA, Sklar P, Hultman CM, Sullivan PF (2013) Genome-wide association analysis identifies 13 new risk loci for schizophrenia. Nat Genet 45:11501159

79. Russo I, Gavello D, Menna E, Vandael D, Veglia C, Morello N, Corradini I, Focchi E, Alfieri A, Angelini C, Bianchi FT, Morellato A, Marcantoni A, Sassoe-Pognetto M, Ottaviani MM, Yekhlef L, Giustetto M, Taverna S, Carabelli V, Matteoli M, Carbone E, Turco E, Defilippi P (2019) p140Cap regulates GABAergic synaptogenesis and development of hippocampal inhibitory circuits. Cereb Cortex 29:91-105

80. Seisenberger C, Specht V, Welling A, Platzer J, Pfeifer A, Kuhbandner S, Striessnig J, Klugbauer N, Feil R, Hofmann F (2000) Functional embryonic cardiomyocytes after disruption of the L-type alpha(1C) $(\mathrm{Ca}(\mathrm{v}) 1.2)$ calcium channel gene in the mouse. J Biol Chem 275:39193-39199

81. Sekera ER, Rudolph HL, Carro SD, Morales MJ, Bett GCL, Rasmusson RL, Wood TD (2017) Depletion of stercobilin in fecal matter from a mouse model of autism spectrum disorders. Metabolomics 13:132

82. Servili E, Trus M, Atlas D (2019) Ion occupancy of the channel pore is critical for triggering excitation-transcription (ET) coupling. Cell Calcium $84: 102102$

83. Servili E, Trus M, Maayan D, Atlas D (2018) Beta-subunit of the voltage-gated $\mathrm{Ca}(2+)$ channel Cav1.2 drives signaling to the nucleus via $\mathrm{H}$ Ras. Proc Natl Acad Sci U S A 115:E8624-e8633

84. Servili E, Trus M, Sajman J, Sherman E, Atlas D (2020) Elevated basal transcription can underlie timothy channel association with autism related disorders. Prog Neurobiol 101820

85. Shi CZ, Soldatov NM (2002) Molecular determinants of voltagedependent slow inactivation of the Ca2+ channel. J Biol Chem 277:68136821 
86. Splawski I, Timothy KW, Decher N, Kumar P, Sachse FB, Beggs AH, Sanguinetti MC, Keating MT (2005) Severe arrhythmia disorder caused by cardiac L-type calcium channel mutations. Proc Natl Acad Sci U S A 102:8089-8096

87. Splawski I, Timothy KW, Sharpe LM, Decher N, Kumar P, Bloise R, Napolitano C, Schwartz PJ, Joseph RM, Condouris K, Tager-Flusberg H, Priori SG, Sanguinetti MC, Keating MT (2004) Ca(v)1.2 calcium channel dysfunction causes a multisystem disorder including arrhythmia and autism. Cell 119:19-31

88. Stotz SC, Hamid J, Spaetgens RL, Jarvis SE, Zamponi GW (2000) Fast inactivation of voltage-dependent calcium channels. A hinged-lid mechanism? J Biol Chem 275:24575-24582

89. Stotz SC, Jarvis SE, Zamponi GW (2004) Functional roles of cytoplasmic loops and pore lining transmembrane helices in the voltagedependent inactivation of HVA calcium channels. J Physiol 554:263-273

90. Tadmouri A, Kiyonaka S, Barbado M, Rousset M, Fablet K, Sawamura S, Bahembera E, Pernet-Gallay K, Arnoult C, Miki T, Sadoul K, Gory-Faure S, Lambrecht C, Lesage F, Akiyama S, Khochbin S, Baulande S, Janssens V, Andrieux A, Dolmetsch R, Ronjat M, Mori Y, De Waard M (2012) Cacnb4 directly couples electrical activity to gene expression, a process defective in juvenile epilepsy. EMBO J 31:3730-3744

91. Tadross MR, Ben Johny M, Yue DT (2010) Molecular endpoints of $\mathrm{Ca} 2+/$ calmodulin- and voltage-dependent inactivation of $\mathrm{Ca}(\mathrm{v}) 1.3$ channels. J Gen Physiol 135:197-215

92. Tadross MR, Yue DT (2010) Systematic mapping of the state dependence of voltage- and $\mathrm{Ca} 2+$-dependent inactivation using simple open-channel measurements. J Gen Physiol 135:217-227

93. Tuluc P, Yarov-Yarovoy V, Benedetti B, Flucher BE (2016) Molecular interactions in the voltage sensor controlling gating properties of $\mathrm{CaV}$ calcium channels. Structure 24:261-271

94. Vandael DH, Marcantoni A, Mahapatra S, Caro A, Ruth P, Zuccotti A, Knipper M, Carbone E (2010) Ca(v)1.3 and BK channels for timing and regulating cell firing. Mol Neurobiol 42:185-198 
95. Vandael DH, Ottaviani MM, Legros C, Lefort C, Guerineau NC, Allio A, Carabelli V, Carbone E (2015) Reduced availability of voltage-gated sodium channels by depolarization or blockade by tetrodotoxin boosts burst firing and catecholamine release in mouse chromaffin cellslabilit. J Physiol 593:905-927

96. Vandael DHF, Zuccotti A, Striessnig J, Carbone E (2012) Ca(V)1.3driven SK channel activation regulates pacemaking and spike frequency adaptation in mouse chromaffin cells. J Neurosci 32:16345-16359

97. Voronina S, Collier D, Chvanov M, Middlehurst B, Beckett AJ, Prior IA, Criddle DN, Begg M, Mikoshiba K, Sutton R, Tepikin AV (2015) The role of $\mathrm{Ca} 2+$ influx in endocytic vacuole formation in pancreatic acinar cells.

Biochem J 465:405-412

98. Wemhöner K, Friedrich C, Stallmeyer B, Coffey AJ, Grace A, Zumhagen S, Seebohm G, Ortiz-Bonnin B, Rinné S, Sachse FB, Schulze-Bahr E, Decher $\mathrm{N}$ (2015) Gain-of-function mutations in the calcium channel CACNA1C (Cav1.2) cause non-syndromic long-QT but not Timothy syndrome. J Mol Cell Cardiol 80:186-195

99. Wheeler DG, Barrett CF, Groth RD, Safa P, Tsien RW (2008) CaMKII locally encodes L-type channel activity to signal to nuclear CREB in excitation-transcription coupling. J Cell Biol 183:849-863

100. Yang SN, Berggren PO (2005) Beta-cell CaV channel regulation in physiology and pathophysiology. Am J Phys Endocrinol Metab 288:E16-E28

101. Yarotskyy V, Gao G, Peterson BZ, Elmslie KS (2008) The Timothy syndrome mutation of cardiac CaV1.2 (L-type) channels: multiple altered gating mechanisms and pharmacological restoration of inactivation. J Physiol 587:551-565

102. Yazawa M, Dolmetsch RE (2013) Modeling Timothy syndrome with iPS cells. J Cardiovasc Transl Res 6:1-9

103. Zamponi GW, Striessnig J, Koschak A, Dolphin AC (2015) The physiology, pathology, and pharmacology of voltage-gated calcium channels and their future therapeutic potential. Pharmacol Rev 67:821-870 